OPEN ACCESS

Edited by:

Keiichi Okazaki,

Niigata University, Japan

Reviewed by:

Yutaka Tabei,

National Agriculture and Food Research Organization (NARO),

Japan

Ryo Ohsawa,

University of Tsukuba, Japan

*Correspondence:

Kevin F. Smith

kfsmith@unimelb.edu.au

Specialty section: This article was submitted to

Plant Breeding,

a section of the journal

Frontiers in Plant Science

Received: 24 July 2019 Accepted: 13 November 2019

Published: 11 December 2019

Citation:

Giraldo PA, Shinozuka H, Spangenberg GC, Cogan NOI and Smith KF (2019) Safety Assessment of Genetically Modified Feed: Is There

Any Difference From Food?

Front. Plant Sci. 10:1592. doi: 10.3389/fp/s.2019.01592

\section{Safety Assessment of Genetically Modified Feed: Is There Any Difference From Food?}

\author{
Paula A. Giraldo 1,2, Hiroshi Shinozuka ${ }^{2}$, German C. Spangenberg ${ }^{2,3}$, Noel O.I. Cogan ${ }^{2,3}$ \\ and Kevin F. Smith ${ }^{1,4 *}$ \\ ${ }^{1}$ Faculty of Veterinary and Agricultural Sciences, The University of Melbourne, Parkville, Melbourne, VIC, Australia, ${ }^{2}$ Agriculture \\ Victoria Research, AgriBio, The Centre for AgriBiosciences, Melbourne, VIC, Australia, ${ }^{3}$ School of Applied Systems Biology, \\ La Trobe University, AgriBio, The Centre for AgriBiosciences, Melbourne, VIC, Australia, ${ }^{4}$ Agriculture Victoria Research, Hamilton, \\ VIC, Australia
}

Food security is one of major concerns for the growing global population. Modern agricultural biotechnologies, such as genetic modification, are a possible solution through enabling an increase of production, more efficient use of natural resources, and reduced environmental impacts. However, new crop varieties with altered genetic materials may be subjected to safety assessments to fulfil the regulatory requirements, prior to marketing. The aim of the assessment is to evaluate the impact of products from the new crop variety on human, animal, and the environmental health. Although, many studies on the risk assessment of genetically modified (GM) food have been published, little consideration to GM feedstuff has been given, despite that between 70 to $90 \%$ of all GM crops and their biomass are used as animal feed. In addition, in some GM plants such as forages that are only used for animal feeds, the assessment of the genetic modification may be of relevance only to livestock feeding. In this article, the regulatory framework of GM crops intended for animal feed is reviewed using the available information on GM food as the baseline. Although, the majority of techniques used for the safety assessment of GM food can be used in GM feed, many plant parts used for livestock feeding are inedible to humans. Therefore, the concentration of novel proteins in different plant tissues and level of exposure to GM feedstuff in the diet of target animals should be considered. A further development of specific methodologies for the assessment of GM crops intended for animal consumption is required, in order to provide a more accurate and standardized assessment to the GM feed safety.

Keywords: traceability, environment, toxicological, allergenicity, forage, transgenic crops, regulatory framework, genome-editing

\section{INTRODUCTION}

The growth of the human population will create significant challenges for agricultural production, making food security a growing issue. Nearly 870 million people suffer from malnutrition, most of them in the developing countries of Africa, Asia, and South America (World Hunger, 2013). Additionally, climate change and environmental degradation are currently reducing the available agricultural land, creating additional challenges to fill the increasing food demand (Hanjra and Qureshi, 2010). The use of modern biotechnology, including genetic modification techniques, has been proposed as a way 
to reduce the environmental footprint, by improving food quality and increasing productivity (Barros et al., 2019).

Animal derived food is a major contributor to human nutrition and health, largely through supplying protein. It also plays a crucial role in rural economies of most developing countries, particularly in dry areas (Godfray et al., 2010). In order to produce enough protein for the growing global population, farming systems are increasing the pressure on land, water resource use and biodiversity conservation. Solutions to face climate change and high demand for natural resources are urgently needed, especially in the area of forage production (Sakadevan and Nguyen, 2017), since it compromises nearly $80 \%$ of the world agricultural land and provides the grazing feed-base for the dairy and red meat industries (Bruinsma, 2017).

Implementation of molecular breeding technologies in forage crops can enhance the agricultural sector through increases in productivity, more efficient use of natural resources and decreases in environmental impacts (Ramessar et al., 2010). Breeding programs target the development of genetic solutions for forage quality limitations, pest and disease resistance, nutrient acquisition efficiency, tolerance to abiotic stresses, and the targeted modification of growth and development (Smith et al., 2007).

Transgenesis is a classical DNA modification methodology, which enables production of crops with desired traits based on the introduced transgene(s). Genome editing technologies were more recently established, which enable alteration of the DNA to produce defined multination(s) and/or insertion of foreign gene(s) at the targeted site(s), in contrast to GM where the insertion is random (Sprink et al., 2016). Genetic modification is typically defined as alteration of the genetic material of an organism in a way, which does not naturally occur (Wolt et al., 2015). Crop cultivars developed through use of transgenesis, therefore, have been regard as GM organisms (Hundleby and Harwood, 2019).

Transgenic crops can be further divided into four classifications/ classes, according to the structure and strategy for transgenesis (Lin and Pan, 2016). Most GM commercially available today are categorized as the first class of transgenics, also called single trait transgenics. These crops typically contain common transgenic elements, such as the 35 s promoter sequence of cauliflower mosaic virus, and nopaline synthase terminator (nos-T) from Agrobacterium (Shaw et al., 1984; Wehrmann et al., 1996). The second class transgenics have stacked modified traits, and these varieties usually result from hybrid crosses of first-generation GM crop varieties. The hybrid cross procedure may increase economic values of the GM variety with a lower development cost. The third class of transgenics are so-called near-intragenics, these are GM crops where the transgene construction originates from the host with some minimal modifications. The last class are more related to true intragenic or cisgenic technologies, where the transgene is comprised of only products and elements from the host, without modifications and the only difference with its conventional counterpart is the specific order and insertion loci of the transgenes (Rommens et al., 2007; Jacobsen and Schouten, 2009; Lin and Pan, 2016).

On the other hand, genome editing technologies use biological tools such as sequence-specific nucleases to generate desired modifications within plant genomes, allowing the introduction of one or more transgenes at a specific locus, the removal of unwanted DNA from the host, or the control in the expression of endogenous or synthetic genes (Songstad et al., 2017).

Since approvals for commercialization of early-generation transgenic crops, safety issues for human consumption have been mainly considered. GM crops as animal feed and GM forage have not been considered as the primary target of the regulatory framework. Although there are some animal feedstuffs that crossover with human consumption (e.g., grain), there are many plants and plant parts that are not directly consumed by humans but are exclusively used by livestock as feed. This review article aims to summarize and discuss the elements needed for the safety assessment of GM crops for animal feed purposes, using the available information on the current practice of safety assessment that the product would be subjected to, as the baseline.

\section{GM FEED}

The market share of GM products has rapidly increased from commercialization of the early generation of GM crops in the 1990s, (I.S.A.A.A., 2017). The major GM crops available in the market are soybean (Glycine max L. Merr.) with $77 \%$ of the global area for individual crops (94.1 million hectares), maize (Zea mays L.) at 32\% (59.7 million hectares), cotton (Gossypium arboretum L.) at $80 \%$ (24.21 million hectares), and canola (Brassica napus L.) $30 \%$ (10.2 million hectares). The commercial use of transgenesisdelivered crops cultivars has also recently expanded to more species including sugar beet (Beta vulgaris L.), papaya (Carica papaya L.), squash (Cucurbita L.), eggplant Solanum melongena L.), potatoes (Solanum tuberosum L.), and apples (Malus pumila Miller, 1768), and these products are already commercially available in US (I.S.A.A.A., 2017). A meta-analysis including 147 food and feed crops, also has revealed that the adoption of GM technology has decreased the use of chemical pesticides by $37 \%$, increased crop yields by $22 \%$, and increased farmer profits by 68\% (Klümper and Qaim, 2014).

GM crops can be traded as food and feed products (Panel on Genetically Modified Organisms, 2010). The products are classified as GM food, when the direct consumers are mainly humans, and the products only intended for animal consumption are regarded as GM feed. However, a range of GM crops, such as maize, soybean, and canola, are used as both food and feed (Figure S1). Most GM crops available in the market, except for alfalfa (Medicago sativa L. ssp. sativa) and creeping bentgrass (Agrostis stolonifera) have been assessed as GM food, because they can be consumed by humans. On the basis of biomass, between 70 to $90 \%$ of all GM crops, however, are estimated to be used in farm as animal feed (Flachowsky et al., 2012).

In contrast to GM food crops, only a few types of GM forage products have been commercially released. Alfalfa is an economically important legume forage mainly in temperate regions. The first GM forage crop commercialized in US was the Roundup Ready ${ }^{\circledR}$ Alfalfa from Forage Genetics International (Nampa, ID, US), which can be categorized as a first generation transgenic (van Deynze et al., 2004). The herbicide-resistance trait was produced through inserting two copies of an Agrobacteriumderived gene (cp4 epsps) of which translational product (EPSPS; 
5-enolpyruvylshikimate-3-phosphate synthase) contribute to glyphosate-tolerance. Such insertion of the foreign gene allows post-emergence applications of glyphosate-based herbicides for weed control (Putnam et al., 2016).

Following to Roundup Ready ${ }^{\circledR}$ Alfalfa, another first-generation transgenic, HarvXtra ${ }^{\mathrm{TM}}$ Alfalfa (Forage Genetics International) was developed and commercially released. Using RNA interference (RNAi)-based gene suppression mechanics, the lignin content and composition are modified in this cultivar. A transgene cassette including an inverted repeat of the interference-targeting sequence was introduced using $A$. tumefaciens for suppression of caffeoyl-CoA 3-O-methyltransferase (CCoAOMT), which is involved in lignin biosynthesis. The inverted repeat was designed to be transcribed under control of the phenylalanine ammonialyase (PAL) 2 promoter from common bean (Phaseolus vulgaris L.) for vascular tissue-specific expression, allowing the desired suppression of lignin biosynthesis without negative effects on forage yield (Barros et al., 2019).

Perennial ryegrass (Lolium perenne L.) is also one of most important forage species in the temperate regions. Although several transgenic perennial ryegrass plants with potentially economically useful traits have been developed, none of them has been commercially released. Using a similar approach to HarvXtra $^{\mathrm{TM}}$ Alfalfa, low-lignin perennial ryegrass individuals have been generated (Hu et al., 2013). In the transgenic perennial ryegrass, lignin biosynthesis-related genes were down-regulated based on the RNAi mechanisms. As the transgenic low-lignin plants may have increased digestibility for cattle, the lignin biosynthesis-controlling technology may be useful for production of optimal feedstocks. The Chimeric REpressor Gene-Silencing Technology (CRES-T) is a newly developed transgenesis-based approach for functional analysis of transcription factors in plants (Mitsuda et al., 2011). A CRES-T transgenic construct was developed to target a zinc finger transcription factor gene, which is negatively related to salt tolerance (Cen et al., 2016). Transgenic perennial ryegrass plants with the CRES-T construct showed a higher tolerance to salt stress (up to $300 \mathrm{mM} \mathrm{NaCl}$ ). Interestingly, the transgenic perennial ryegrass also showed a vigorous phenotype under non-salt stress condition, which may be useful for forage breeding purposes.

Perennial ryegrass plants with a high-energy trait have been also developed, using the transgenic technologies. A synthesized construct of perennial ryegrass 6-glucose fructosyltransferase (6G-FFT) and sucrose:sucrose 1-fructosyl-transferase (1SST) genes were introduced into the perennial ryegrass genome, aiming enhancement of fructan biosynthesis in the leaf blades (Panter et al., 2017). The transgenic plants showed a substantial increment in fructan accumulation in leaf blades, as well as enhanced biomass production. These traits could be beneficial for the livestock industry, as leaf blades are the major part as feed for grazing ruminants (Lee et al., 2003). The transgenic plants were generated through insertion of manipulated perennial ryegrass genes, and this cultivar can be regarded as a third generation transgenic.

Improvement of biotic stress tolerance in white Clover (Trifolium repens L.), an important pasture legume in temperate regions, has been also developed through the generation of plants immune to infection by Alfalfa mosaic virus (AMV)
(Smith et al., 2007). Although, this AMV resistant clover has not been commercially released yet, different studies have demonstrated the expression and stability of the viral coat protein gene encoded, by the sub-genomic RNA4 of AMV in white clover, under glass house and field conditions (Panter et al., 2012; Smith and Spangenberg, 2016).

Forage crops improvements, via genetic modifications and genome editing, have the potential to play a key role in fulfilling the increasing demand for animal products. Therefore, risk assessment must ensure its safety for humans, animals, and the environment, in order to have an agricultural system economically and environmentally sustainable.

\section{GM OR GE?}

Genome edited (GE) plants are gaining popularity and are still classified as GMs in some jurisdictions, so the authors considered it necessary to address the issues on these crops as well in this manuscript. Both GM and GE crops and their products are required to be subjected to rigorous evaluations as a part of several regulatory requirements before their commercial release into the market. The legislation for GM and GE crops is based on the principle of assuring the safety of humans, animals, and the environment. Comprehensive studies on the risk assessment of GM food crops have been published previously (König et al., 2004; Delaney, 2015; Domingo, 2016; Gurău and Ranchhod, 2016; Dadgarnejad et al., 2017; Tutel'yan, 2017; De Santis et al., 2018; Kumar et al., 2018).

Some variation between regulatory frameworks of GM crops exists across jurisdictions. In the US, safety assessment of new GM crops is mainly performed though comparison with conventional counterparts, to provide scientific evidence that GM products can be considered as safe as a conventional product, if the characteristics and composition are substantially equivalent (FAO/WHO, 2000). The assessment of the Canadian authority also focuses on the products itself (Alexandrova et al., 2005). European regulation focuses more on the certification of the genetic modification process, instead of the products (European Parliament, 2001), as well as Argentina, Japan, and South Africa (Seyran and Craig, 2018). The Australian regulatory authority, the Office of the Gene Technology Regulator (OGTR), has followed a safety assessment model promoted by the World Trade Organization (WTO). Such model has provided as general guideline that safety assessment of GM plants should include consideration of the risk for humans, animals, and environment, and should be science-based (Dibden et al., 2013).

Similarly, there is variation in the regulation of GE products compare with GM across jurisdictions with much of the debate being polarized (Jones, 2015). Some regulatory bodies argue that genome editing techniques are very similar to those used to produce GMOs, so they should be regulated similarly (Seyran and Craig, 2018). However, the scientific community argues that unintended effects can always occur, regardless of the types of techniques used for crop development (Fernandez and Paoletti, 2018).

From a scientific point of view, the number of alleles changed in the process of traditional breeding, such as crossing and 
selection of superior genotype combinations, should be typically higher than that of transgenesis or genome-editing approach. With other breeding techniques such as radiation and chemicalbased mutagenesis, there is no established method for most crop species, to accurately assess the number of genes changed. In case of soybean, a combination of high-throughput DNA sequencing and molecular cytogenetics-based copy number variations assay, suggested that single nucleotide substitutions and structural variations generated during Agrobacterium-based transgenesis, was substantially less than those of radioactive-based mutagenesis (Anderson et al., 2016). The same approaches, also indicated that the frequencies of single nucleotide substitutions and structural variations generated through the transgenesis and mutagenesis, were considerably less than those found between existing soybean cultivars.

Different breeding techniques and their requirement for safety assessment before commercialization are described in Figure S2. Traditional breeding and mutagenesis, in general, change a high number of genes and mutations generally involve loss of function, while GM offers the advantage of knowing the actual gene(s) being inserted and usually involves a gain of function (Gepts, 2002). Nevertheless, the regulatory system assesses plants resulting from hybridization, radiation, or chemical induced mutagenesis, which may produce thousands of uncharacterized random mutations, as non-GM crops (Urnov et al., 2018). A recently published article that evaluates the impact of the risk assessment on public acceptance, concluded that the rigorous regulatory vigilance of modern biotechnology (transgenesis and gene editing), leads to public distrust and contribute to the idea that GM crops are unsafe. Therefore, a risk-disproportionate regulation of these technologies not only confuses the purpose of risk assessment, but also interferes with the delivery of beneficial technologies to the market (Herman et al., 2019).

As a result of such opinion polarization between the scientific community and regulatory bodies, the Court of Justice of the European Union (CJEU; Luxembourg) has decided to classify genome-editing technologies as genetic modification, submitting this plant-breeding approach to severe GM regulations and risk evaluation (Eriksson, 2019). In contrast, both the United States and Canada regulate new crop varieties according to their characteristics rather than by the method with which they are produced (Wolt, 2017). Therefore, gene-edited products without any transgene and with history of production and safe consumption, do not require special regulations (Hundleby and Harwood, 2019). The regulations implemented in the United States and Canada, is shared by a number of bodies including the UK's Biotechnology and Biological Sciences Research Council, the German Academies, the European Plant Science Organization, and the French High Council for Biotechnology (Laaninen, 2016).

Recently, the Australian regulator gene technology regulator (OGTR) has made amendments to make the legal position of genome editing clearer. These amendments clarify that organisms modified by SDN-1 (Site-Directed Nuclease 1) techniques, present no different risk than organisms carrying naturally occurring genetic changes, and do not require unnecessary regulation (OGTR, 2019). Although in many jurisdictions, a conclusive regulatory decision has not been provided, it is possible that the position regarding GE products of the United States, Canada, Australia, and some European national regulators, will affect regulatory decisions in other countries and regions.

Both GM and GE belong to the same or similar plant biotechnology applications. In some cases, plants are transformed using recombinant DNA to introduce the GE tools, and then, they are self-pollinated or crossed to remove the incorporated DNA, leaving only the intended mutation (Metje-Sprink et al., 2020). This ability of GE to produce changes without the integration of recombinant DNA can avoid GM regulations in some countries. The reduced risk of DNA integration into the genome provided by GE, along with the indirect human exposure to GM feed, can have great implications in the commercialization of new GE feeds.

\section{LABELING POLICIES}

Since the commercialization of the first GM crop in the mid90s, some consumer groups have argued for more detailed and comprehensive labeling or extensive labeling to enable choice for the purchaser (Halle, 2008). Therefore, in response to the difficulty of maintaining zero tolerances, each jurisdiction has established a tolerance threshold for the involuntary or inevitable presence of GM material in non-GM products. If the amount of GM material in a product exceeds the tolerance threshold, the products should be labeled as containing GM material (Devos et al., 2009).

Labeling policies can include a ban on labeling, voluntary labeling indicating that a product is GM free, or mandatory labeling indicating that a product contains GM. When the latter is implemented, a legal tolerance threshold is set, and it also varies between countries, making trade and shipment of goods complex. In the US, Canada and Japan for instance, the legal tolerance threshold for conventional food and feed products has been set at 5\%. Australia, New Zealand, South Africa, Brazil and China have tolerance thresholds at $1 \%$, while in the European Union if a commercial product has more than $0.9 \%$ of GM material, it must be labeled as a GM product to inform consumers (Ramessar et al., 2010). Most countries have GM mandatory labeling laws, however, the US authority regards the nature of the product more critical than the process itself, so that GM labeling may be voluntary (Huffman and McCluskey, 2017).

To date, mandatory GM labeling laws, however, have largely excluded products from animals fed with GM feed (such as meat, milk, and eggs) as well as GM processing aids and enzymes (such as rennet for making cheese) (Van-Eenennaam and Young, 2017). In Europe, the labeling requirements (European Regulation 1830/2003; European Parliament, 2003) on GM food and feed, results in those agricultural products not requiring labeling. However, some EU member countries have established regulations and guidelines to label animal products voluntarily as non-GM, to allow consumers to choose products where no GM feed stuff were directly used in its production (Venus et al., 2018).

Even though food products derived from animals fed with GM feed crops do not require labeling, the safety assessment procedure for GM feed crops is the same than for GM food. 
Regulatory bodies have based such decision on the fact that it is impossible to prevent the contact of GM feed material with humans, during cultivation, transport and storage of the crops (Food Standards Australia and New Zealand, 2014).

\section{SAFETY ASSESSMENT}

The scientific evidence that must be provided in the safety assessment of GM crops can vary among different legal jurisdictions (Alexandrova et al., 2005). However, a detailed molecular characterization of the transgene insertion, development of tracking and tracing methodologies to ensure legality and traceability, and environmental studies to enable coexistence frameworks, are common studies in the safety assessment of GM crops (Van Haver et al., 2003). Other studies, such as toxicological, allergenicity, nutritional, and horizontal transfer, have been performed following a case-bycase approach considering newly emerging scientific knowledge and technologies (König et al., 2004). The use of GM crops as a feed can reduce concerns around human safety and underline other features such as feeding value and nutritional equivalence (Flachowsky et al., 2002).

From an industrial point of view, the assessment required for the regulatory authorities could be divided into two groups; pre- and post-marketing issues. The former includes relatively standard technologies for all GM food and feed, such as molecular characterization and development of tracking and tracing tools for traceability purposes. Pre-marketing issues also involves technologies under development that varies on a caseby-case basis, including environmental, food/feed, toxicological, and allergenicity safety studies. Post-marketing issues are related with regulatory monitoring, which contemplate GM labeling and traceability (Figure S3).

\section{Molecular Characterization}

Molecular characterization of GM crops is a full description of the structural information of the transgene and stability of the trait ( $\mathrm{Li}$ et al., 2017). It is the foundation of all GM product safety assessments before commercialization and also serves as a baseline for the development of detection and identification tools to satisfy traceability and labeling requirements (European Parliament, 2003). Stakeholders of both GM food and feed, must provide information on the genomic locus/loci modified, copy number of the inserted transgene, insertion site, and flanking regions (Guttikonda et al., 2016).

Selection of low insertion copy number DNA transformants is preferred for the subsequent safety assessment process as it facilitates risk and hazard characterization (Tiwari and Singh, 2018). The methods most commonly used to determinate the number of transgenes integrated have been Southern blot analysis and polymerase chain reaction (PCR), in its various formats such as real-time PCR (qPCR) (Li et al., 2017).

The Southern blot analysis involves a careful selection and broad screening of restriction enzymes and designing of probes, which in some cases dependent on prior sequence information of the transgene insertion (Urquiza and Silva, 2014). However, the approach is relatively time-consuming and laborious, and also includes a manual interpretation process. In addition, the result may not accurately reflect the copy number of a transgene, if sequence rearrangements have occurred, which have affected the position(s) of the restriction enzyme recognition site(s) in the inserted transgene(s) (Yang et al., 2005).

A qPCR-based assay can more accurately quantify the copy number of transgenes by comparing to an endogenous reference sequence (endogene), which has provided a simplified alternative to Southern blot analysis (Li et al., 2017). However, identification of a single copy reference gene is occasionally difficult in crop species, due to ancestral whole genome duplications or due to polyploidy, causing complex structures and genetic redundancy (Ren et al., 2018). To overcome the identification of a reference gene and dependency on DNA calibrations, droplet digital PCR (ddPCR), a method that identifies the absolute DNA copy number in a sample, has been proposed for determination of GM copy number (Głowacka et al., 2016; Dalmira et al., 2016).

Following identification of low-copy number transformants, the precise location(s) of the transgene(s) in the crop genome is required to be identified (Park et al., 2017). DNA sequencing approaches have been used for this purpose, and this process may also identify backbone sequence(s), which were not intended to be introduced from the transformation vector into the host genome (Kononov et al., 1997). The method traditionally used for this purpose was based on Sanger sequencing (Guttikonda et al., 2016). However, the second-generation sequencing (SGS) technologies have been proposed as a new tool for molecular characterization of GM crops, due to a larger sequencing capacity and potentially higher accuracy of the resulting assembled sequence (Kovalic et al., 2012; Yang et al., 2013; Pauwels et al., 2015; Arulandhu et al., 2016).

The SGS approaches can increase speed, scalability, and automation in the selection of potential valuable events on the basis of their molecular profile, facilitating post-transformation screening (Kovalic et al., 2012; Pauwels et al., 2015; Guttikonda et al., 2016). However, these technologies do not directly provide information about the position of the insertion(s) in native DNA, due to short read lengths (50-400 base pairs) (Goodwin et al., 2016), while transgenic constructs are typically thousands of base pairs. A computational process for alignment and/or assembly of the short sequencing reads is essential for the molecular characterization purposes, and repetitive elements commonly found in plant genomes can generate problems for the alignment/ assembly procedure (Liang et al., 2014).

Recently, single-molecule sequencing, also termed third-generation sequencing (TGS) platforms, have been commercialized allowing a large increase in read length up to tens of thousands of bases per read (Loose et al., 2016). Read length is limited by the input DNA fragment size, but over 300 $\mathrm{kb}$ have been reported (Jain et al., 2016). The increment in read lengths up to tens of thousands can facilitate a more reliable GM characterization process, by extending the sequence reads of the flanking regions present in the captured fragments and potentially solving alignment problems. 
The most common TGS platforms are products from Pacific Biosciences (PacBio, Menlo Park, CA, US) and Oxford Nanopore Technologies (ONT Oxford Science Park, Oxford). PacBio uses a sequencing-by-synthesis method to capture a single DNA molecule and a circular consensus sequence (CCS) to increase accuracy. The CCS uses a circular DNA template by ligating hairpin adaptors to both ends of target double-stranded DNA, so the DNA template is sequenced multiple times to generate a continuous long read (Weirather et al., 2017). Nanopore sequencing, uses nanopores to sequence native single-stranded DNA, by measuring the changes in an electric current passed across the pore as the DNA bases pass through, disrupting the current to different levels with different nucleotides (Giordano et al., 2017).

Nanopore sequencing offers potential benefits in molecular characterization of GM products compared with PacBio, since it delivers raw data in real-time, is relatively easy to manipulate, and has low setup costs. The MinION from ONT is a portable device that has been successfully assessed for detection of unauthorized GM products (Fraiture et al., 2018). Further assessment demonstrated the capability of the MinION to determine the full molecular characterization of three transgenic crops (ryegrass, canola and clover) within 48 hours.

Although, new guidelines are emerging from regulatory bodies to generate pre-market submission of data using whole genome sequencing (Health Canada, 2019) and NGS (UCD Centre for Food Safety et al., 2018). Sequencing approaches are typically being used in tandem, for example Sanger sequencing with SGS or SGS with TGS, for verification and validation purposes during risk assessment of GM crops (Boutigny et al., 2019).

In short, GM forage species including Alfalfa (Barros et al., 2019), Switchgrass (Dumitrache et al., 2017), Sorghum (Rooney et al., 2007) have been characterized adopting the same technologies used for GM food. However, the expression of introduced traits in plant parts not used for food, should be considered. For instance, a GM plant can be produced with specific production of the $\mathrm{Bt}$ toxin only in leaves, preventing insect attack and removing the exposure of humans to the compound when consuming its grains (OECD, 2003). However, in such cases those plant parts would substantially increase the exposure of animals to the GM toxin when consuming them, and this difference must be taken into account in the molecular characterization.

\section{GM Traceability}

GM traceability describes a system that enables tracking of GM food/feed products at all stages of the supply chain (Giraldo et al., 2019). Detection methods for GM products in different matrixes or substrates, such as grain, flour and forage, are not only important to ensure legality and traceability, but also to comply with GM labeling regulations (European Parliament, 2003).

Methods for GM detection and identification usually rely on certified reference materials that are in powdered form, however, routine detection must be performed in different agricultural and food products (Cankar et al., 2006). The selection of DNA extraction protocols is of crucial importance, since the DNA can be present in low amounts, carrying inhibitors or degraded (SanJuan-Badillo et al., 2014). Therefore, the extraction method should be evaluated for each agricultural product, guaranteeing high DNA yield and purity (Turkec et al., 2015).

The method chosen to comply to traceability and labeling requirements, should be sensitive enough to detect the transgene(s) at levels below the corresponding jurisdiction tolerance threshold (e.g., 5\% in US, $1 \%$ AU, and $0.9 \%$ in EU) (Ramessar et al., 2010). Additionally, it should be able to detect the transgene(s) from raw agricultural commodities entering the feed production chain. For instance, fresh leaves, dry leaves (hay), pollen, seeds, tillers or stems, and forage that could enter the feed chain as unprocessed material (Ardizzone et al., 2018; Giraldo et al., 2019).

Currently, qPCR is the standard method used in national reference laboratories for detection and quantification of GM events (Dalmira et al., 2016). The requirement for reference material to be used as calibrants, which sometimes are not commercially available, limits its effectiveness (Dobnik et al., 2016; Dalmira et al., 2016). The GM product detection process followed by national reference laboratories consist of two consecutive steps; first, a qPCR screening of vectors commonly found in GM products, such as the $35 \mathrm{~S}$ promoter from cauliflower mosaic virus, Agrobacterium tumefaciens (tNOS) and selectable markers. Then, the samples with a potential presence of GM materials, are tested using the corresponding GM event-specific method (Fraiture et al., 2017).

Droplet digital PCR (ddPCR) technologies use the same DNA amplification principles as qPCR, but the technologies can provide a higher quantification precision through partitioning PCR mix into thousands of nanoliter-sized droplets in which PCR amplification is carried out (Dobnik et al., 2016; Dalmira et al., 2016). Features such as absolute quantification, avoidance of using standard curves, and high resilience to inhibitors, makes ddPCR a promising alternative for GM event detection (Rački et al., 2014; Corbisier et al., 2015).

SGS technologies have also been proposed to comply with the requirements for GM traceability due to the ability to detect all target sequences in multiple samples without the development and validation of target-specific methods and reference material (Arulandhu et al., 2018). However, the requirement of bioinformatics knowledge for data analysis and more sophisticated devices limits its use in routine GM event detection (Park et al., 2017). Figure S4 compares qPCR, ddPCR, and SGS in terms of GM identification and quantification, multiplexing capacity and ability to detect known and unknown sequences. It also underlines that the cost and processing time increase from qPCR to ddPCR and to SGS.

In recent years, significant effort has been performed to replace the time-consuming and expensive qPCR screening procedure (Holst-Jensen et al., 2016; Salisu et al., 2017). As a result, other technologies are been evaluated including ddPCR (Dalmira et al., 2016; Dobnik et al., 2015; Köppel et al., 2015; Demeke et al., 2016; Dobnik et al., 2016; Gerdes et al., 2016; Głowacka et al., 2016; Iwobi et al., 2016; Grelewska-Nowotko et al., 2018; Niu et al., 2018; Corbisier and Emons, 2019; Giraldo et al., 2019), SGS (Willems et al., 2016; Fraiture et al., 
2017; Arulandhu et al., 2018), DNA enrichment approaches (Arulandhu et al., 2016) and combined strategies of DNA walking and SGS (Fraiture et al., 2017).

However, all the above methods are lab-based and time consuming, so that the development of rapid and portable devices with more routine throughput screening methods are likely to continue into the immediate future. Recent research related to on-site detection of GM crops include; loop-mediated isothermal amplification (LAMP) (Hardinge et al., 2018; Singh et al., 2019; Loo et al., 2019), LAMP and a lateral flow biosensor (Cheng et al., 2017), PCR and a lateral flow biosensor (Gao et al., 2019), handheld field-portable qPCR systems (Nguyen et al., 2018; Russell et al., 2018), and nanopore sequencing (Fraiture et al., 2018; Russell et al., 2018).

Technologies to fulfil regulatory requirements for GM food traceability have been established. The qPCR-based method is suitable for a high-throughput screening of transgene(s), and the ddPCR-based approach can provide a higher accuracy of the measured GM product concentration, especially at a low level. Although, the same approaches of GM food may be used for GM feed to comply the regulatory requirements, for GM feedstuff special considerations should be given to the use of plant parts not used for human food and by-products from other industries using GM plants (OECD, 2003).

\section{Environmental Safety Studies}

Environmental risk assessments (ERA) aim to determine whether a new GM crop variety has direct effects on the natural environment (Hilbeck et al., 2011; Devos et al., 2016). Although a range of factors, such as effects on biodiversity, modification of soil and water quality, and disease and weed control, must be considered in this process, the major concern of ERA is gene flow (GF) of the transgene(s) to wild relatives (Warwick et al., 2009).

GF is a result of the movement of gametes or individuals from a specific population to another, which may generate a significant change in the allele frequency of the receiving population (Slatkin, 1987). This phenomenon not only has been observed between populations of the same species, but also between closely related species (Wilson and Manhart, 1993; Bartsch et al., 2002). In case of natural plant populations, such movement can happen via seeds, vegetative propagules or pollen and its importance varies among plant species (Tsatsakis et al, 2017). General approaches to quantify GF use foreign herbicide and antibiotic resistance genes to provide insight into the rates and importance of hybridization (Mallory-Smith et al., 2015). However, morphological and molecular markers are also required to assist with rapid identification or to identify/confirm hybrids.

To allow GM and non-GM crops to exits in mutual tolerance and minimize undesired GF, a concept defined by the term "coexistence" was introduced. Coexistence refers to the right that consumers have to choose between conventional, organic, and GM crop production, in compliance with the legal obligations for labeling defined in each jurisdiction (Devos et al., 2009). Although, different varieties of the same species have coexisted prior to appearance of GM crop variety, the need for the strategies to manage the consequence of inadvertent fertilization have become more outstanding with the commercial release of GM crops (Ramessar et al., 2010).

A potential risk of transgenes GF is cross-pollination between GM crops and native species, which has been intensively discussed since the commercial realize of GM plants (Messeguer, 2003; Kuparinen et al., 2007; Warwick et al., 2009; Tsatsakis et al., 2017). Pollen-mediated GF has been reported during production of commercial GM crops including maize, rapeseed, cotton, soybean, and creeping bentgrass (Reichman et al., 2006; Chifflet et al., 2011; Baltazar et al., 2015; Rizov and Rodriguez-Cerezo, 2015; Loureiro et al., 2016; respectively).

One of the most common coexistence measures to reduce pollen-mediated GF is isolation distances. It is defined as the minimum distance between GM and non-GM crop fields of the same species that should prevent a cross-pollination rate from reaching to threshold levels (Cunliffe et al., 2004). Multiple factors, such as population size, distance, and flowering synchrony between donor and receiver fields, as well as local wind conditions, all influence the determination of an appropriate isolation distances (Devos et al., 2009).

Different isolations distances have been determinate to avoid or minimize cross-fertilization between GM and non-GM fields. Table 1 describes different isolation distances required for the four major GM crops (maize, canola, soybean, and cotton), to maintain cross-fertilization ratio below legal tolerance thresholds. For instance, to maintain cross-fertilization levels below $1 \%$ an isolation distance of $20 \mathrm{~m}$ is require for maize (Baltazar et al., 2015), $9 \mathrm{~m}$ or more for cotton (Baltazar et al., 2015), and $5 \mathrm{~m}$ for soybean (Rizov and Rodriguez-Cerezo, 2015).

In GM forage species, undesired pollination can be the major type of GF, since forage grass species typically exhibit a highly outcrossed nature and are wind-pollinated (Holme et al., 2013). Smith and Spangenberg (2016) reviewed the most important coexistence strategies in outcrossing forage species, highlighting that a coexistence framework for the dominant cross-pollinated grain crops (canola and maize) is already well established in Europe, as well as alfalfa in the US. Hence, existing principles such as development of detection techniques, segregation and agronomic management can be applied to other forage crops when developing coexistence frameworks.

TABLE 1 | Cross-fertilization level in different isolation distances for the major forage crops commercially available.

\begin{tabular}{lccc}
\hline Crop & Isolation distance & $\begin{array}{c}\text { Cross-fertilization } \\
\text { level }\end{array}$ & Reference \\
\hline Maize & $50 \mathrm{~m}$ & $<0.5 \%$ & $\begin{array}{c}\text { Sanvido et al., 2008 } \\
\text { Canola }\end{array}$ \\
Soybean & $30 \mathrm{~m}$ & $<1 \%$ & Baltazar et al., 2015 \\
& $33-200 \mathrm{~m}$ & $<0.03 \%$ & Staniland et al., 2000 \\
& $5 \mathrm{~m}$ & $0.9 \%$ & Cai et al., 2008 \\
Cotton & $10 \mathrm{~m}$ & $0.1 \%$ & Rizov and Rodriguez- \\
& $10 \mathrm{~m}$ & $<0.9 \%$ & Cerezo, 2015 \\
Alfalfa & $>9 \mathrm{~m}$ & $<0.1 \%$ & Loureiro et al., 2016 \\
& $150 \mathrm{~m}$ & $1.39 \%$ & Fitzpatrick et al., 2003 \\
& $500 \mathrm{~m}$ & $0.08 \%$ &
\end{tabular}


Compared with commercially available grain crops, studies on pollen-mediated GF in wind-pollinated forages is scarce. A study on transgenic alfalfa (Medicago sativa L.) using the cp4 epsps transgene as marker, showed that a $500-\mathrm{m}$ isolation distance is required for maintenance of the cross-fertilization level below 0.1\% (Fitzpatrick et al., 2003). Rigid ryegrass (Lolium rigidum) gene flow was reduced from $37.8 \%$ at $0 \mathrm{~m}$ and $0.93 \%$ at $100 \mathrm{~m}$ (Busi et al., 2008). In other species with high levels of self-compatibility such as barnyardgrass (Echinochloa crus-galli), cross-fertilization rates at 0 -m distance was $12.5 \%$ (Bagavathiannan and Norsworthy, 2014) and for tall fescue (Festuca arundinacea) 5\% were detected at $50 \mathrm{~m}$ and less than $1 \%$ at $150 \mathrm{~m}$ (Wang et al., 2004).

Transgenic GF of the commercial GM grains has been intensively studied and discussed as a main part of ERA, some of such information can be apply to GM forage crops, the potential risks may be depending on the nature of transgenic traits. For GM forages considerations such as life cycle, since forage crops are largely perennial not annual or biannual, can have repercussions on pollen flow and it can remove management of gene flow through farming systems temporally.

Different regulations and laws about GM plants create complexities for the movement of agricultural products between borders and has a significant impact on international trade. The Cartagena Protocol on Biosafety is an international treaty that aims to protect biodiversity from the potential risk of GMO resulting from modern biotechnology. Such Protocol dictates that GM plants should follow the precautionary principle, which states that "In order to protect the environment, the precautionary approach shall be widely applied by States according to their capabilities" (Secretariat of the Convention on Biological Diversity, 2000). Therefore, standardized methods of ERA for GM crops has not been established and it is managed by individual laws in each country. Usually, a case-by-case assessment needs to be performed and the methods used for GM food and feed are the same.

\section{Feed Safety Studies}

The vast majority of forage crop products are fed to livestock; hence, any human consumption of GM feedstuff is an indirect effect and can easily be regulated and mitigated to ensure complete safety. Feed safety studies examine whether the genetic modification could unintentionally increase the potential toxicity or allergenicity of the transgenic plant for humans or animals, as well as changes in nutritional characteristics (Pauwels et al., 2015). As forage crop products are predominantly eaten by animals and human consumption of GM feedstuff represents an indirect effect, and this type of assessment should be unique to GM feed. Feeding studies focus on answering three main issues; substantial equivalence, the safety of the new crop for humans and animals, and the safety of the product derived from animals raised on transgenic feed. Those issues are comprehensively discussed in Aumaitre et al. (2002) and Ramessar et al. (2007).

According to The Organization for Economic Co-operation and Development (OECD), the substantial equivalence concept refers to the idea that existing food products can serve as a basis for comparison when assessing the nutritional value and safety of food modified by modern biotechnological methods (OECD, 1993). This comparison helps quantify the effect of the transgene as well as understanding the variation in the natural species for the trait being modified. The analysis of chemical composition would serve as the first step for the nutritional evaluation. Such comparison is, however, largely based on the premise that an existing cultivar with a history of safe use, can serve as a comparator when evaluating the safety of a GM food/feed (Flachowsky et al., 2012). The type of comparators, key characteristics selected, and interpretation of compositional data may vary change among different countries. The OECD, an intergovernmental organization in which representatives of 30 industrialized countries in North America, Europe, and the Pacific, have consensus documents about common GM plants, which are a valuable source to ensure a consistent assessment (OECD, 2000).

Some examples of GM products that passed the substantial equivalence test include a maize line with the sb401 gene incorporated to increase lysine content, the equivalent test with a conventional protein quality maize (Nongda 108) showed that the lysine-rich maize was safe (Tang et al., 2013). The compositional equivalence of a herbicide-tolerant rice (Bar 68-1) exhibited no significant differences, when compared with its isoline (D68) (Li et al., 2008). The evaluation of a Bt soybean (products Mon $87701 *$ Mon 89,788 ) that confers pest resistance and glyphosate resistance, concluded that $B t$ soybean was as safe as its traditional counterparts (Berman et al., 2009). Similarly, Bollgard II cotton (event 15985) with insect resistance properties was compared with traditional cotton varieties, and the results demonstrate that it was as safe and nutritious as conventional cotton for food and feed use (Hamilton et al., 2004).

When substantial equivalence of GM feed product to its traditional analogues cannot be concluded, a further assessment comprises of the following steps: in silico, or in vitro preliminary studies, the study of nutritional value of the products; quotas in the diets of animals; methods of use in nutrition, and during lactation; digestibility, evaluation of intake of individual components (if the expected intake is more than $15 \%$ of the daily requirement); impact on the intestinal microflora (if GM product contains live microorganisms) (Levitsky 2016). The safety assessment of each country can be different and in some jurisdiction animal experiments are not required. For instance, the OECD consider that GM plants where compositional analyses demonstrate no significant differences from the comparator, animal feeding studies with target species will add little to a safety assessment, so that nutritional equivalence can be assumed (OECD, 2003).

As a part of assessment for animal safety issues, the in silico, or in vitro studies also can provide an estimation of the impact of GM feed in the nutrition of target animals, prior to the feeding studies involving animals. In silico evaluation may serve to identify changes in key nutritional components and in vitro simulated gastric and intestinal fluids to study the digestive stability of novel proteins (ILSI, 2007; DBT, 2008). All laboratory studies should be conducted according to the internationally recognized guidelines (OECD, 1998). The information obtained from these studies help to determine the need for future in vivo studies with target animals (EFSA, 2008). The OECD has 
developed guidelines for different animal and in vitro testing (OECD, 1995: Guidelines 401, 407, 408, 414, 415, 416, 420, 421, $423,425,451,452,453,474,475,478,486)$.

Tudisco and Infascelli (2014) used an in vitro gas production technique to compare the nutritional value of GM corn and soybean with their traditional counterparts. They found that the fermentation kinetics of GM corn and gas production of GM soybean were respectively faster and lower compared with their counterparts. Another in vitro experiment using batch fermentation models assessed the possibility of transfer of crylAb transgene to porcine jejunal microbiota, concluding that the transfer of transgene was not detected (Buzoianu et al., 2012a).

Swiatkiewicz et al. (2014), comprehensively reviewed the published information on health status, blood parameters, immunological characteristics, histopathological examination of cattle, poultry and fish. Concluding that the quality and potential risks for human consumption of livestock products such as meat, milk, and eggs and the metabolic parameters were not significantly affected when livestock were fed with commercialized GM crops. Although, there is a large proportion of studies on livestock animals, most of them focuses on the possibility of horizontal gene transfer (HGT) from GM crops to animal tissues.

Feeding test, using model animals has been conducted for a safety assessment of GM food crops. The main animal species, which would consume the GM feed products are, however, livestock, such as cattle, sheep, swine, and poultry (Nadal et al., 2018). Cattle (dairy and beef) and sheep belong to the ruminant category, with a unique digestive system that gives them the ability to obtain nutrients from forage crops by breaking down its cellulose content in a special stomach compartment using microbial actions. On the other hand, swine have a monogastric digestive system with an enzymatic stomach very similar to humans, and poultry have an avian digestive system without teeth to chew the feed (France et al., 2006). Cattle and sheep are herbivores, whereby their diet is mainly forage-based, while swine, poultry, and humans are omnivores, so they eat mostly grains and some plants (Flanders and Gillespie, 2015).

Until now the safety assessment of GM plants has focused in human exposure, animal safety while not ignored, has received less importance (Aumaitre et al., 2002). Pigs have been widely used as models for humans, because of their similar gut anatomy and physiology (especially mucosal immunity) and nutritional requirements (Ladics et al., 2010). Rodent tests have received the greatest importance from regulatory bodies, especially for toxicological and allergenicity studies of the products of introduced genes. However, these animals are not usually feed with the entire GM plant or their by-products, while livestock animals have greater exposure to GM feedstuff, compromising a high percentage of their diet on a daily basis and often for their complete lifespan (Aumaitre et al., 2002). Additionally, variations in the livestock system can determine the evaluation profile, for instance, forage grasses will be relevant to ruminant species and have little to no value to monogastric species.

Due to their anatomical and eating habits differences, it is impossible to assess the safety of a transgenic GM feed with a single and unified test. A more specialized case-by-case approach is essential for the safety assessment of GM feed. Development of standardized in silico and in vitro approaches, can reduce time and cost for this process and avoid the use of animals. When required, in vivo feed studies offer the possibility of conducting feeding trials in the target species, something not possible with GM food in humans.

\section{Toxicological Studies}

The purpose of toxicological studies is to characterize intended changes and detect active substances or compounds that could have unexpected toxic effects for non-targeted organisms (Van Haver et al., 2003). All toxicity assessment for GM material should be performed based on a case-by-case approach, considering the toxicological profile of new introduced substances (Domingo, 2007).

The methods to assess the toxicity of a specific compound in the body, usually compromise the use of animal studies, considering the target species and the critical effects (Levitsky, 2016). However, new strategies to identify GM feed anti-nutrient or toxicants include research on the in-planta metabolism pathway, such as "-omics" techniques that may generate a better understanding of the complex pleotropic effects of new plant cultivars (Fernandez and Paoletti, 2018). Additionally, in vitro assays with gastric enzymes, cultured cell lines, receptor proteins, and in vivo animal studies can be performed (Van Haver et al., 2003).

High-throughput “-omics" profiling techniques, which involve the use of metabolomics, transcriptomics, and proteomics, have been suggested as a nontargeted approach to detect unintended effects in GM crops (Ricroch, 2013). Profiling studies using omics techniques include GM glyphosate-tolerant soybean, where some specific metabolites were different compared with the isogenic line and the results were explained by modifications in the regulation of the shikimate pathway (Garcia-Villalba et al., 2008). Nevertheless, a GM stacked rice carrying the herbicide-resistant gene bar and insect-resistance cry, was found substantially equivalent to its conventional genetic breeding and natural genetic cultivars, when their proteome profiles were compared (Gong et al., 2012). A review of the safety assessment of GM crops using omics techniques, indicated that transgenesis has less unintended impacts than conventional breeding (Ricroch, 2013). Another study showed that there were more transcriptomic alterations in mutagenized plants than transgenic plants (Batista et al., 2008).

Several toxicological studies in GM feed using omics techniques, involve the analysis of fungus or their secondary metabolites. For instance, mycotoxins, which are undesired substances produced by crop-related fungus. In hybrids Bt maize, one of the principal components of feeding formulas for livestock, plants experienced less fumonisin concentration compare with its isoline (Bowers et al., 2014). It was hypothesized that the reduction of fumonisins was due to the pest reduction in the GM maize, since the fungus spore migration and colonization may be facilitated with damages from insects. Therefore, it could be concluded that GM corn can provide reductions in the risk of fumonisins contamination, but not increment of toxicological risk for animals. 
Similarly, in the transgenic high-energy perennial ryegrass, an evaluation of alkaloids, secondary metabolites produced by endophytic fungus, found that the alkaloids concentration in transgenic plants was same or lower compare with the isogenic line. The lower alkaloid concentration could be partly attributed to higher growth of transgenic plants, which could generate a dilution effect in the modulation of fungal biomass (Giraldo et al., 2018).

When performing in vivo studies, toxicology acute (14 days studies), subacute (28 days studies), chronic (90 days studies), or specific toxicity (reproductive, mutagenicity, etc.) assessment can be considered (Levitsky, 2016). In a chronic study feeding mice with crushed Bt cotton seeds, cry genes and tnos promoter were detected only in intestinal tissue, while they were not found in stomach, blood, liver, kidney, heart, and brain (Sajjad et al., 2014). In long term studies ( $>100$ days), no toxic effects were found in cattle and chickens fed with $B t$ maize. They concluded that short fragments of plant chloroplasts ( $<200$ base pairs) can be detected in blood lymphocytes of cattle, but DNA fragments were not detected in other organs investigated (muscle, liver, spleen and kidney) (Einspanier et al., 2001). Similarly, some small changes in the metabolic profile of sheep fed with Bt176-maize were found when compared with non-GE maize, according to the authors such changes did not represent a health hazard (Snell et al., 2012). In pigs fed with Bt maize (MON810 event), although all serum biochemistry parameters were within the normal reference interval for pigs, small differences were reported. The authors concluded that the differences were the result of a lower enzymeresistant starch in the GM compare with the non-GM control (Buzoianu et al., 2012b).

Safety assessments of GM feeds should consider the maximum level present in any plant part consumed by animals or in any by-product used as a feed ingredient, since the introduced traits can express differently in the plant parts, affecting the concentration of novel proteins. This can have implications in the level of exposure, selection of comparators and determination of the novel protein concentration used in acute/sub-chronic toxicity studies (OECD, 2003).

In short, a case-by-case approach is also required for toxicological assessment of GM crops, and the assessment procedure has not been standardized. A comparison with conventional counterparts has been a common approach for GM food products, and a similar approach may be used for forage products. A more cautious and stringent examination may be required for GM feed, due to that a wider range of plant organs may be used for animal consumption than those for human consumption, and storage conditions of the GM forage products may be less uniformed and controlled than GM food.

\section{Allergenicity Studies}

Allergenicity and toxicological studies may be assessed at once, since both are designed to detect newly expressed substances. Allergenic reactions can cause more severe symptoms, but usually to only some individuals, while toxicity is predictable and reproducible between individuals as it affects the majority of exposed individuals with only minor differences in susceptibility (De Santis et al., 2018).

In US, concerns about potential risks for allergy have arisen from GM food crops, including one under development for several times. A $2 \mathrm{~S}$ albumins gene from Brazil nut was introduced into a soybean cultivar, for a purpose of nutritional enhancement. The transgene products, however, were identified to have potential allergic risks for human, especially those with allergy to the Brazil nut, and development of the GM soybean cultivar was suspended (Moreno and Clemente, 2008; Delaney, 2015). Concerns for the Cry9C protein, a type of insect pest resistance protein from bacillus also arose, due to a higher stability to heat and possible prolong time for digestion (Wiedinmyer et al., 2000). As a consequence, the StarLink maize, an unauthorized maize containing the Cry9C transgene, was not approved for human consumption by the US authority (Zhang et al., 2016).

In case of a GM feed safety assessment, both human and animals may need to be included in an allergenicity study as test subjects. An allergenicity assessment for animals could be performed with a similar approach to that for human. There is, however, currently no standardized procedure to predict allergenic reactions to non-endogenous proteins even in humans. The European Food Safety Authority (EFSA) has recommended using animal models to evaluate the sensitizing potential of novel proteins on a case-by-case basis (Marsteller et al., 2015). The most common species to assess GM allergenicity are rodents, also referred to as a rat 90-day evaluation, which is now compulsory in the EU for new GM crops (Hong et al., 2017). However, the published studies on rats, mice, and pigs, aimed to assess the allergic risk of humans (Ladics et al., 2010), using animals mostly as food allergy models.

The most common approaches to assess allergenicity include amino-acid sequence homology, in vitro digestibility tests, serum screening and animal models (Van Haver et al., 2003). Amino acid sequence homology or similarity uses bioinformatic methods to determine the possibility, that a novel protein can be closely similar to a known allergen that can create a risk of crossreactions (Naegeli et al., 2017). However, such bioinformatic methods cannot predict the likelihood that the novel protein might become a de novo allergen, so other methods like in vitro digestibility tests, serum screening, and animal models may need to be used (Ladics et al., 2010). The in vitro pepsin resistance assay is the most commonly used protein digestion test, which provide information about the susceptibility of a novel protein to digestion. This assay can be used as an additional evidence of possible adverse reactions to GM food/feed, since gastrointestinal digestion can affect the immunogenicity of dietary proteins related to both IgE and non-IgE reactions (Naegeli et al., 2017).

Serum screening and immunoassays are alternative ways to assess endogenous allergens, using sera from individuals with relevant allergies. Although, these types of assays are the current reference method for in vitro detection and definition of an allergenic proteins, detection of allergic animals pose limitations for the applicability in the safety assessment of GM feed. Alternatively, there are other analytical and molecular profiling techniques, which can serve as alternative tests for 
the comparative assessment of the endogenous allergenicity between the GM plant and its non-GM comparator (Fernandez et al., 2013).

Information on immunological responses, and particularly allergenic reactions on livestock fed with GM products is scarce and is likely to need more extensive research. Nevertheless, allergenicity assessment of GM feed offers the advantage of direct evaluations in target species, something not possible with GM food in humans.

\section{Horizontal Gene Transfer}

HGT refers to the movement of a genetic material to a living cell or organism across boundaries between species. In the case of GM organisms, movement of transgene(s) into other species, especially microorganism, or natural population of the taxonomically related species have been concerned, as such transfer may have impacts on human/animal health, and natural environments. (EFSA, 2007; EFSA, 2009; ADAS, 2013; Nicolia et al., 2014; Van Eenennaam and Young, 2014; Giacomo et al., 2016). This section relates to environmental, feed safety, toxicological, and allergenicity studies, since the transfer of recombinant DNA into other organisms can affect the health of humans, animals, and the environment.

Although assessment of the digestion fate of recombinant DNA or its new proteins can be performed using in vitro gastric or intestinal fluid-based digestion systems to assess HGT in bacteria (Fuchs et al., 1993; Wehrman et al., 1996; Entransfood 2004; Sharma et al., 2004; Bertrand et al., 2005), studies using cattle species have been also commonly conducted evaluating the digestive process of recombinant DNA and proteins from feedstuff (Faust and Miller, 1997; Ash et al., 2000; Aulrich et al., 2001; Jennings et al., 2003; Aumaitre, 2004; Phipps et al., 2005; FASS, 2006; Rizzi et al., 2012; Swiatkiewicz et al., 2014; Van Eenennaam and Young, 2014; Levitsky, 2016; Van Eenennaam and Young, 2017; Nadal et al., 2018). For example, recombinant DNA has been found in ruminal solid phase and duodenal digesta of cattle, but the DNA was not detected in liquid ruminal and duodenal phase, as well as milk, blood, and faeces. Those results indicate a rapid degradation of the transgene in the first digestive stages (Phipps et al., 2003).

In studies using cows fed with transgenic maize, recombinant DNA was not detected from milk (Faust and Miller, 1997; Giacomo et al., 2016), blood, muscle, kidneys, liver, or spleen (Einspanier et al., 2001). Also, recombinant DNA was not detected from milk of cows grown with feed including up to $26 \%$ of transgenic glyphosate-tolerant soybean (Phipps et al., 2002). Similarly, in studies on poultry fed with transgenic maize, recombinant DNA was not detected from muscle, kidneys, liver, and spleen, as well as eggs (Einspanier et al., 2001). Only a little possibility of incorporation of recombinant DNA into the genomes of human or animal of digestive organs has been suggested from some of these studies, and the majority of the studies concluded that such risk of horizontal transfer of transgene is insignificant (Chambers et al., 2002; Ramessar, et al., 2007; Levitsky, 2016). As the risk of incorporation of recombinant DNA into germ cells should be even lower, the possibility of inheritance of the recombinant DNA into the following generation should be insignificant.

In case of GM feed products, possible risks on human health may need to be also considered, as the products are indirectly consumed by human via cattle. The rapid digestion process of recombinant DNA, evidenced by the studies described above, suggests that the indirect risks on human health are low. The safety of food products produced from animals feed on transgenic crops has also been widely studied, and in the majority of studies, any recombinant DNA was not found in animal products. However, in a couple cases, short fragments of the recombinant DNA were detected in milk (Phipps et al., 2002; Agodi et al., 2006). The authors, however, interpreted their presence as a contamination of faecal or airborne material with feed particles (Agodi et al., 2006).

Most of the scientific finding till the date has not found significant risk directly related with the consumption of GM crops and these findings can be extrapolated to forage species. In general, proteins derived from recombinant DNA, as any protein, are degraded in the gastro-intestinal tract, while dietary DNA is not totally degraded and, in some cases, small fragments can be found into animal tissues (Nadal et al., 2018).

\section{CONCLUSION}

The use of molecular breeding technologies such as genetic modification and genome editing in forage crop species can help farmers address the challenges of climate change, sustainability, and global food security. Information about the safety assessment of GM forage crops intended only for animal feeding is scarce, even though most of GM products and its biomass is destined for livestock animals feeding. The regulatory assessment scheme is designed for GM food and a similar approach can be used for the assessment of forage crops considering the differences in risk profile of the contrasting outcomes.

The same techniques used for molecular characterization, GM traceability, environmental safety studies and HGT can be used for both GM food and feed. However, specific adjustments to the techniques may be required, considering that parts of the GM plant used to feed livestock may have different concentrations of the novel proteins, changing its level of exposure. Feed, toxicological, and allergenicity studies for GM feed only destined for animal consumption are not well defined. The design of specific strategies to cover GM feed safety can be more targeted for the safety of species that are going to consume the crop, while also potentially having a lower regulatory cost.

A new framework for the risk assessment procedure, for both GM food and feed, is necessary in order to make a more efficient use of resources and avoid unnecessary evaluation. The final aim should be to assess GM novel crops in a more effective way, to increase the commercialization of products with potential to provide economic and health benefits to consumers and producers. 


\section{AUTHOR CONTRIBUTIONS}

PG has written the manuscript under the supervision and drafting of HS, NC, and KS. The review was finally edited by HS, GS, NC, and KS.

\section{FUNDING}

This work was supported by funding from Agriculture Victoria Research and an Australian Government Research Training Program Scholarship for PG.

\section{REFERENCES}

ADAS. (2013). Review of the strategies for the comprehensive food and feed safety and nutritional assessment of GM plants per se. EFSA Support. Publ. EN-480, 115. doi: 10.2903/sp.efsa.2013.EN-480

Agodi, A., Barchitta, M., Grillo, A., and Sciacca, S. (2006). Detection of genetically modified DNA sequences in milk from the Italian market. Int. J. Hyg. Environ. Health 209, 81-88. doi: 10.1016/j.ijheh.2005.08.005

Alexandrova, N., Georgieva, K., and Atanassov, A. (2005). Biosafety regulations of GMOs: national and international aspects and regional cooperation. Biotechnol. Biotechnol. Equip. 19 (sup3), 153-172. doi: 10.1080/13102818.2005.10817294

Anderson, J. E., Michno, J. M., Kono, T. J., Stec, A. O., Campbell, B. W., Curtin, S. J., et al. (2016). Genomic variation and DNA repair associated with soybean transgenesis: a comparison to cultivars and mutagenized plants. BMC Biotechnol. 16 (1), 41. doi: 10.1186/s12896-016-0271-Z

Arulandhu, A. J., van Dijk, J. P., Dobnik, D., Holst-Jensen, A., Shi, J., Zel, J., et al. (2016). DNA enrichment approaches to identify unauthorized genetically modified organisms (GMOs). Anal. Bioanal. Chem. 408 (17), 4575-4593. doi: 10.1007/s00216-016-9513-0

Arulandhu, A. J., van Dijk, J., Staats, M., Hagelaar, R., Voorhuijzen, M., Molenaar, B., et al. (2018). NGS-based amplicon sequencing approach; towards a new era in GMO screening and detection. Food Control 93, 201-210. doi: 10.1016/j.foodcont.2018.06.014

Ash, J. A., Scheideler, E., and Novak, C. L. (2000). The fate of genetically modified protein from Roundup Ready soybeans in the laying hen. Poult. Sci. 79 (Suppl. 1), 26. doi: 10.1093/japr/12.2.242

Aulrich, K., Böhme, H., Daenicke, R., Halle, I., and Flachowsky, G. (2001). Genetically modified feeds in animal nutrition. 1st Com.: Bacillus thuringiensis (Bt) corn in poultry, pig and ruminant nutrition. Arch. Anim. Nutr. 54, 183195. doi: 10.1080/17450390109381977

Aumaitre, A., Aulrich, K., Chesson, A., Flachowsky, G., and Piva, G. (2002). New feeds from genetically modified plants: substantial equivalence, nutritional equivalence, digestibility, and safety for animals and the food chain. Livest. Prod. Sci. 74, 223-238. doi: 10.1016/S0301-6226(02)00016-7

Aumaitre, A. (2004). Safety assessment and feeding value for pigs, poultry and ruminant animals of pest protected $(\mathrm{Bt})$ plants and herbicide tolerant (glyphosate, glufosinate) plants: interpretation of experimental results observed worldwide on GM plants. Ital. J. Anim. Sci. 3, 107-121. doi: 10.4081/ ijas.2004.107

Ardizzone, M., Paoletti, C., and Waigmann, E. (2018). Explanatory note on the selection of forage material suitable for the risk assessment of GM feed of plant origin. EFSA Supporting Publications, vol. 15, no. 1, p. 1366E.

Bagavathiannan, M. V., and Norsworthy, J. K. (2014). Pollen-mediated transfer of herbicide resistance in Echinochloa crus-galli. Pest Manag. Sci. 70, 1425-1431. doi: $10.1002 / \mathrm{ps} .3775$

Baltazar, B. M., Castro Espinoza, L., Espinoza-Banda, A., de la Fuente-Martínez, J. M., Garzón-Tiznado, J. A., González-García, J., et al. (2015). Pollen-mediated gene flow in maize: implications for isolation requirements and coexistence in mexico, the center of origin of maize. PloS One 10 (7), e0131549. doi: 10.1371/ journal.pone.0131549

\section{SUPPLEMENTARY MATERIAL}

The Supplementary Material for this article can be found online at: https://www.frontiersin.org/articles/10.3389/fpls.2019.01592/ full\#supplementary-material

FIGURE S1 | Difference between GM food and feed.

FIGURE S2 | Different breeding techniques and its requirement for safety assessment before commercialisation.

FIGURE S3 | Pre and pos-marketing issues to be solve before GM crops commercialisation.

FIGURE S4 | Comparison of qPCR, ddPCR and NGS.

Barros, J., Temple, S., and Dixon, R. A. (2019). Development and commercialization of reduced lignin alfalfa. Curr. Opin. In Biotechnol. 56, 48-54. doi: 10.1016/j. copbio.2018.09.003

Bartsch, D., Lehnen, M., Clegg, J., Pohl-Orf, M., Schuphan, I. I., and Ellstrand, N. C. (2002). Impact of gene flow from cultivated beet on genetic diversity of wild sea beet populations. Mol. Ecol. 8 (10), 1733-1741. doi: 10.1046/j.1365-294x.1999.00769.x

Batista, R., Saibo, N., Lourenco, T., and Oliveira, M. (2008). Microarray analyses reveal that plant mutagenesis may induce more transcriptomic changes than transgene insertion. Proc. Natl. Acad. Sci. U. S. A. 105, 3640-3645. doi: 10.1073/ pnas.0707881105

Berman, K. H., Harrigan, G. G., Riordan, S. G., Nemeth, M. A., Hanson, C., Smith, M., et al. (2009). Compositions of seed, forage, and processed fractions from insect-protected soybean Mon 87701 are equivalent to those of conventional soybean. J. Agric. Food Chem. 57, 11360-11369. doi: 10.1021/jf902955r

Bertrand, A., Joly, P. B., and Marris, C. (2005). L'expérience française d’évaluation technologique interactive sur les vignes transgéniques. Ethique Publique 7 (1), 186-194. doi: 10.4000/ethiquepublique.2006

Boutigny, A. L., Barranger, A., De Boisséson, C., Blanchard, Y., and Rolland, M. (2019). Targeted next generation sequencing to study insert stability in genetically modified plants. Sci. Rep. 9 (1), 2308. doi: 10.1038/s41598-019-38701-9

Bowers, E., Hellmich, R., and Munkvold, G. (2014). Comparison of fumonisin contamination using HPLC and ELISA methods in Bt and near-isogenic maize hybrids infested with European corn borer or Western bean cutworm. J. Agric. Food Chem. 62 (27), 6463-6472. doi: 10.1021/jf5011897

Bruinsma, J. (2017). World agriculture: towards 2015/2030: an FAO study. Routledge.

Busi, R., Qin, Y., Barrett-Lennard, R., and Powles, S. (2008). Long distance pollenmediated flow of herbicide resistance genes in Lolium rigidum. Theor. Appl. Gen. 117, 1281-1290. doi: 10.1007/s00122-008-0862-8

Buzoianu S. G, Walsh M. C, Rea M. C, O'Sullivan O, Crispie F, Cotter P. D, et al. (2012a) The effect of feeding bt mon 810 maize to pigs for 110 days on intestinal microbiota. PLoS ONE 7 (5), e33668. doi: 10.1371/journal.pone.0033668

Buzoianu, S. G., Walsh, M. C., Rea, M. C., Cassidy, J. P., Ross, R. P., Gardiner, G. E., et al. (2012b). Effect of feeding genetically modified Bt MON810 maize to 40-day-old pigs for 110 days on growth and health indicators. Animal 6 (10), 1609-1619. doi: 10.1017/S1751731112000249

Cai, L., Zhou, B., Guo, X., Dong, C., Hu, X., Hou, M., et al. (2008). Pollen-mediated gene flow in Chinese commercial fields of glufosinate-resistant canola (Brassica napus). Chin. Sci. Bull. 53 (15), 2333. doi: 10.1007/s11434-008-0305-6

Cankar, K., Štebih, D., Dreo, T., Žel, J., and Gruden, K. (2006). Critical points of DNA quantification by real-time PCR-effects of DNA extraction method and sample matrix on quantification of genetically modified organisms. BMC Biotechnol. 6 (1), 37. doi: 10.1186/1472-6750-6-37

Cen, H., Ye, W., Liu, Y., Li, D., Wang, K., and Zhang, W. (2016). Overexpression of a chimeric gene, OsDST-SRDX, improved salt tolerance of perennial ryegrass. Sci. Rep. 6, 27320. doi: 10.1038/srep27320

Chambers, P. A., Duggan, P. S., Heritage, J., and Forbes, J. M. (2002). The fate of antibiotic resistance marker genes in transgenic plant feed material fed to chickens. J. Antimicrob. Chemother. 49, 161-164. doi: 10.1093/jac/49.1.161 
Cheng, N., Shang, Y., Xu, Y., Zhang, L., Luo, Y., Huang, K., et al. (2017). On-site detection of stacked genetically modified soybean based on event-specific TM-LAMP and a DNAzyme-lateral flow biosensor. Biosensors Bioelectronics 91, 408-416. doi: 10.1016/j.bios.2016.12.066

Chifflet, R., Klein, E. K., Lavigne, C., Le Feon, V., Ricroch. A.E. Lecomte, J., et al. (2011). Spatial scale of insect-mediated pollen dispersal in oilseed rape in an open agricultural landscape. J. Appl. Ecol. 48, 689-696. doi: 10.1111/j. 1365-2664.2010.01904.x

Corbisier, P., and Emons, H. (2019). Towards metrologically traceable and comparable results in GM quantification. Anal. Bioanal. Chem. 411 (1), 7-11. doi: 10.1007/s00216-018-1457-0

Corbisier, P., Pinheiro, L., Mazoua, S., Kortekaas, A. M., Chung, P. Y. J., Gerganova, T., et al. (2015). DNA copy number concentration measured by digital and droplet digital quantitative PCR using certified reference materials. Anal. Bioanal. Chem. 407 (7), 1831-1840. doi: 10.1007/s00216-015-8458-z

Cunliffe, K. V., Vecchies, A. C., Jones, E. S., Kearney, G. A., Forster, J. W., Spangenberg, G. C., et al. (2004). Assessment of gene flow using tetraploid genotypes of perennial ryegrass (Lolium perenne L.). Aust. J. Agric. Res. 55, 389-396. doi: 10.1071/AR03156

Dadgarnejad, M., Kouser, S., and Moslemi, M. (2017). Genetically modified foods: promises, challenges and safety assessments. Appl. Food Biotechnol. 4 (4), 193202. doi: $10.22037 /$ afb.v4i4.17244

Dalmira, F. U., Melina, P. U., José-Benigno, V. T., Josefina, L. F., Raymundo, G. E., and Abraham, A. S. (2016). Development, optimization, and evaluation of a duplex droplet digital PCR assay to quantify the T-nos/hmg copy number ratio in genetically modified maize. Anal. Chem. 88 (1), 812-819. doi: 10.1021/acs. analchem. 5 b03238

DBT (Department Biotechnology). (2008). Protocols for food and feed safety assessment of GE crops. Dept. Biotechn. Min. Sci. Technol. India.

De Santis, B., Stockhofe, N., Wal, J. M., Weesendorp, E., Lallès, J. P., van Dijk, J., et al. (2018). Case studies on genetically modified organisms (GMOs): potential risk scenarios and associated health indicators. Food Chem. Toxicol. 117, 36-65. doi: 10.1016/j.fct.2017.08.033

Delaney, B. (2015). Safety assessment of foods from genetically modified crops in countries with developing economies. Food Chem. Toxicol. 86, 132-143. doi: 10.1016/j.fct.2015.10.001

Demeke, T., Holigroski, M., Eng, M., and Xing, J. (2016). Absolute quantification of genetically engineered traits with droplet digital PCR: Effect of DNA treatments and spiking with non-target DNA. Food Control 68, 105-111. doi: 10.1016/j.foodcont.2016.03.007

Devos, Y., Demont, M., Dillen, K., Reheul, D., Kaiser, M., and Sanvido, O. (2009). Coexistence of genetically modified and Non-GM crops in the european union: a review. Sustain. Agric. 29, 11-30. doi: 10.1007/978-90-481-2666-8_14

Devos, Y., Gaugitsch, H., Gray, A. J., Maltby, L., Martin, J., Pettis, J. S., et al. (2016). Advancing environmental risk assessment of regulated products under EFSA's remit. EFSA J. 14, e00508. doi: 10.2903/j.efsa.2016.s0508

Dibden, J., Gibbs, D., and Cocklin, C. (2013). Framing GM crops as a food security solution. J. Rural Stud. 29, 59-70. doi: 10.1016/j.jrurstud.2011.11.001

Dobnik, D., Spilsberg, B., Bogožalec Košir, A., Holst-Jensen, A., and Žel, J. (2015). Multiplex quantification of 12 European Union authorized genetically modified maize lines with droplet digital polymerase chain reaction. Anal. Chem. 87 (16), 8218-8226. doi: 10.1021/acs.analchem.5b01208

Dobnik, D., Štebih, D., Blejec, A., Morisset, D., and Žel, J. (2016). Multiplex quantification of four DNA targets in one reaction with Bio-Rad droplet digital PCR system for GMO detection. Sci. Rep. 6, 1-9. doi: 10.1038/srep35451

Domingo, J. L. (2007). Toxicity studies of genetically modified plants: a review of the published literature. Crit. Rev. Food Sci. Nutr. 47(8), 721-733.

Domingo, J. L. (2016). Safety assessment of GM plants: an updated review of the scientific literature. Food Chem. Toxicol. 95, 12-18. doi: 10.1016/j. fct.2016.06.013

Dumitrache, A., Natzke, J., Rodriguez Jr, M., Yee, K. L., Thompson, O. A., Poovaiah, C. R., et al. (2017). Transgenic switchgrass (Panicum virgatum L.) targeted for reduced recalcitrance to bioconversion: a 2-year comparative analysis of field-grown lines modified for target gene or genetic element expression. Plant Biotechnol. J. 15(6), 688-697.

EFSA (European Food Safety Authority). (2009). Scientific opinion of the panel on genetically modified organisms on a request from the European Commission related to the safeguard clause invoked by Austria on oilseed rape GT73 according to Article 23 of Directive 2001/18/EC. EFSA J. 1151, 1-16. doi: 10.2903/j.efsa.2009.1151

EFSA. (2007). EFSA reaffirms its risk assessment of genetically modified maize MON 863. Available from: http://www.efsa.europa.eu/en/press/news/ gmo070628.htm [last accessed 1 Aug 2013].

EFSA. (2008). Safety and nutritional assessment of GM plants and derived food and feed: the role of animal feeding trials. Food Chem. Toxicol.: Int. J. Publ. Br. Ind. Biol. Res. Assoc. 46, S2. doi: 10.1016/j.fct.2008.02.008

Einspanier, R., Klotz, A., Kraft, J., Aulrich, K., Poser, R., Schwagele, F., et al. (2001). The fate of forage plant DNA in farm animals: a collaborative case-study investigating cattle and chicken fed recombinant plant material. Eur. Food Res. Technol. 212, 129-134. doi: 10.1007/s002170000248

Entransfood, the European network on safety assessment of genetically modified food crops (2004). Genetically modified crops in the EU: food safety assessment, regulation, and public concerns. Overarching report. European commission.

Eriksson, D. (2019). The evolving EU regulatory framework for precision breeding. Theor. Appl. Genet. 132 (3), 569-573, doi: 10.1007/s00122-018-3200-9

European Parliament. (2001). Directive 2001/18/EC of the European Parliament and of the Council of 12 March 2001 on the deliberate release into the environment of genetically modified organisms and repealing Council Directive 90/220/EEC. Off. J. Eur. Commun. L106, 1-39.

European Parliament. (2003). Regulation (EC) 1829/2003 of the European Parliament and of the Council of 22 September 2003 on genetically modified food and feed. J. Eur. Comm. L268, 1-23. doi: 10.1016/S1351-4210(03)00718-2

FASS. (2006). Federation of animal science societies. (Site accessed May 2006) http://www.fass.org/.

Faust, M., and Miller, L. (1997). Study finds no Bt in milk. IC-478. Fall special livestock edition. Iowa State University Extension, Ames, Iowa, 6 p.

Fernandez, A., and Paoletti, C. (2018). Unintended effects in genetically modified food/feed safety: a way forward. Trends In Biotechnol. 36 (9), 872-875. doi: 10.1021/acs.analchem.5b03238

Fernandez, A., Mills, E. N. C., Lovik, M., Spoek, A., Germini, A., Mikalsen, A., et al. (2013). Endogenous allergens and compositional analysis in the allergenicity assessment of genetically modified plants. Food Chem. Toxicol. 62, 1-6. doi: 10.1016/j.tibtech.2018.03.005

Fitzpatrick, S., Reisen, P., and McCaslin, M. (2003). Pollen-mediated gene flow in alfalfa: a three-year summary of field research. In Proceedings of the 2003 central alfalfa improvement conference, virtual meeting, July, pp. 21-25. doi: 10.1016/j.fct.2013.08.023

Flachowsky, G., Aulrich, K., Berk, A., Daenicke, R., and Reuter, T. (2002). Nutritional assessment of feeds from genetically modified (GM) crops. Proc. Soc. Nutr. Physiol. 11, 183-186.

Flachowsky, G., Schafft, H., and Meyer, U. (2012). Animal feeding studies for nutritional and safety assessments of feeds from genetically modified plants: A review. J. Für Verbrauch. und Lebensm. 7 (3), 179-194. doi: 10.22358/ jafs/70020/2001

Flanders, F., and Gillespie, J. R. (2015). Modern Livestock \& Poultry Production. 9th edition, Boston, MA: Cengage Learning. 242-246. doi: 10.1007/ s00003-012-0777-9

Food and Agriculture Organization/World Health Organization. (2000). Report of a Joint FAO/WHO Expert Consultation on Foods Derived from Biotechnology - Safety Aspects of Genetically Modified Foods of Plant Origin, FAO/WHO.

Food Standards Australia New Zealand. (2014). Approval Report - Application A1085. Food derived from Reduced Lignin Lucerne Line KK179. In http:// www.foodstandards.gov.au/code/applications/Documents/A1085-GMAppR.pdf.

Fraiture, M. A., Herman, P., Papazova, N., De Loose, M., Deforce, D., Ruttink, T., et al. (2017). An integrated strategy combining DNA walking and NGS to detect GMOs. Food Chem. 232, 351-358. doi: 10.1016/j.foodchem.2017. 03.067

Fraiture, M. A., Saltykova, A., Hoffman, S., Winand, R., Deforce, D., Vanneste, K., et al. (2018). Nanopore sequencing technology: a new route for the fast detection of unauthorized GMO. Sci. Rep. 8 (1), 7903. doi: 10.1016/j. foodchem.2017.03.067

France, J., Dijkstra, J., Bannink, A., and Gerrits, W. J. (2006). Nutrient digestion and utilization in farm animals: modelling approaches. Wallingford, UK: CAB International, 383-406. doi: 10.1038/s41598-018-26259-x 
Fuchs, R. L., Ream, J. E., Hammond, B. G., Naylor, M. W., Leimgruber, R. M., and Berberich, S. A. (1993). Safety assessment of the neomycin phosphotransferase-II (NPTII) protein. Bio/Technol 11, 1543-1547. doi: $10.1038 /$ nbt1293-1543

Głowacka, K., Kromdijk, J., Leonelli, L., Niyogi, K. K., Clemente, T. E., and Long, S. P. (2016). An evaluation of new and established methods to determine T-DNA copy number and homozygosity in transgenic plants. Plant Cell Environ. 39 (4), 908917. doi: 10.1111/pce.12693

Gao, W., Tian, J., Huang, K., Yang, Z., Xu, W., and Luo, Y. (2019). Ultrafast, universal and visual screening of dual genetically modified elements based on dual super PCR and a lateral flow biosensor. Food Chem. 279, 246-251. doi: 10.1038/ nbt1293-1543

Garcia-Villalba, R., Leonn, C., Dinelli, G., Segura-Carretero, A., FernandezGutierrez, A., Garcia-Canas, V., et al. (2008). Comparative metabolomic study of transgenic versus conventional soybean using capillary electrophoresistime-of-flight mass spectrometry. J. Chromatogr. 1195, 164-173. doi: 10.1016/j. foodchem.2018.12.013

Gepts, P. (2002). A comparison between crop domestication, classical plant breeding, and genetic engineering. Crop Sci. 42 (6), 1780-1790. doi: 10.1016/j. chroma.2008.05.018

Gerdes, L., Iwobi, A., Busch, U., and Pecoraro, S. (2016). Optimization of digital droplet polymerase chain reaction for quantification of genetically modified organisms. Biomol. Detect. Quantif. 7, 9-20. doi: 10.2135/cropsci2002.1780

Giacomo, M., De-Domenicantonio, C., Di-Santis, B., De-Debegnach, F., Onori, R., and Brera, C. (2016). Carry-over of DNA from genetically modified soya bean and maize to cow's milk. J. Anim. Feed Sci. 25, 109-115. doi: 10.1016/j. bdq.2015.12.003

Giordano, F., Aigrain, L., Quail, M. A., Coupland, P., Bonfield, J. K., Davies, R. M., et al. (2017). De novo yeast genome assemblies from MinION, PacBio and MiSeq platforms. Sci. Rep. 7 (1), 3935. doi: 10.22358/jafs/65570/2016

Giraldo, P. A., Elliott, C., Badenhorst, P., Kearney, G., Spangenberg, G. C., Cogan, N. O., et al. (2018). Evaluation of endophyte toxin production and its interaction with transgenic perennial ryegrass (Lolium perenne L.) with altered expression of fructosyltransferases. Transgenic Res. 27(5), 397-407. doi: 10.3389/fpls.2018.01923

Giraldo, P. A., Cogan, N., Spangenberg, G., Smith, K., and Shinozuka, H. (2019). Development and application of droplet digital PCR tools for the detection of transgenes in pastures and pasture-based products. Front. In Plant Sci. 9, 1923. doi: 10.1038/s41598-017-03996-z

Godfray, H. C. J., Beddington, J. R., Crute, I. R., Haddad, L., Lawrence, D., Muir, J. F., et al. (2010). Food security: the challenge of feeding 9 billion people. Science 327, 812-818. doi: 10.1111/pce.12693

Gong, C. H., Li, Q., Yu, H. T., Wang, Z., and Wang, T. (2012). Proteomics insight into the biological safety of transgenic modification of rice as compared with conventional genetic breeding and spontaneous genotypic variation. J. Proteome Res. 11 (5), 3019-3029. doi: 10.1126/science.1185383

Goodwin, S., McPherson, J. D., and McCombie, W. R. (2016). Coming of age: ten years of next-generation sequencing technologies. Nat. Rev. Genet. 17, 333351. doi: $10.1021 /$ pr300148w

Grelewska-Nowotko, K., Żurawska-Zajfert, M., Żmijewska, E., and Sowa, S. (2018). Optimization and Verification of Droplet Digital PCR Even-Specific Methods for the Quantification of GM Maize DAS1507 and NK603. Appl. Biochem. Biotechnol. 185 (1), 207-220. doi: 10.1038/nrg.2016.49

Gurău, C., and Ranchhod, A. (2016). The futures of genetically-modified foods: Global threat or panacea? Futures 83, 24-36. doi: 10.1007/s12010-0172634-x

Guttikonda, S. K., Marri, P., Mammadov, J., Ye, L., Soe, K., Richey, K., et al. (2016). Molecular characterization of transgenic events using next generation sequencing approach. PloS One 11 (2), e0149515. doi: 10.1016/j.futures.2016. 06.007

Halle, M. (2008). "Gmos and theWTORules". Oct. 24. presented at the International Institute for Sustainable Development, Minskdoi: 10.1371/ journal.pone.0149515.

Hamilton, K. A., Pyla, P. D., Breeze, M., Olson, T., Li, M. H., Robinson, E., et al. (2004). Bollgard II cotton: compositional analysis and feeding studies of cottonseed from insect-protected cotton (Gossypium hirsutum L.) producing the Cry1Ac and Cry2Ab2 proteins. J. Agric. Food Chem. 52, 6969-6976. doi: $10.1021 / \mathrm{jf} 030727 \mathrm{~h}$
Hanjra, M. A., and Qureshi, M. E. (2010). Global water crisis and future food security in an era of climate change. Food Policy 35 (5), 365-377. doi: 10.1021/ if030727h

Hardinge, P., Kiddle, G., Tisi, L., and Murray, J. A. (2018). Optimised LAMP allows single copy detection of 35Sp and NOSt in transgenic maize using bioluminescent assay in real time (BART). Sci. Rep. 8 (1), 17590. doi: 10.1016/j. foodpol.2010.05.006

Health Canada. (2019). "Guidance for submitting whole genome sequencing (WGS) data to support the pre-market assessment of novel foods, novel feeds, and plants with novel traits". Canadian Food Inspection Agency. Government of Canada. 10 January, 2019. http://inspection.gc.ca/animals/feeds/novelfeeds/guidance/eng/1547154845895/1547154883652 doi: 10.1038/s41598-01836207-4.

Herman, R. A., Fedorova, M., and Storer, N. P. (2019). Will Following the Regulatory Script for GMOs Promote Public Acceptance of Gene-Edited Crops? Trends In Biotechnol. 37 (12), 1272-1273. doi: 10.1016/j.tibtech.2019. 06.007

Hilbeck, A., Meier, M., Römbke, J., Jänsch, S., Teichmann, H., and Tappeser, B. (2011). Environmental risk assessment of genetically modified plants - concepts and controversies. Environ. Sci. Eur. 23 (1), 13. doi: 10.1016/j. tibtech.2019.06.007

Holme, I. B., Wendt, T., and Holm, P. B. (2013). Intragenesis and cisgenesis as alternatives to transgenic crop development. Plant Biotech. J. 11 (4), 395-407. doi: 10.1186/2190-4715-23-13

Holst-Jensen, A., Spilsberg, B., Arulandhu, A. J., Kok, E., Shi, J., and Zel, J. (2016). Application of whole genome shotgun sequencing for detection and characterization of genetically modified organisms and derived products. Anal. Bioanal. Chem. 408 (17), 4595-4614. doi: 10.1007/s00216-0169549-1

Hong, B., Du, Y., Mukerji, P., Roper, J. M., and Appenzeller, L. M. (2017). Safety assessment of food and feed from GM crops in Europe: evaluating EFSA's alternative framework for the rat 90-day feeding study. J. Agric. Food Chem. 65 (27), 5545-5560. doi: 10.1021/acs.jafc.7b01492

Hu, K., Yan, X., Li, D., Tang, X., Yang, H., Wang, Y., et al. (2013). Genetic improvement of perennial ryegrass with low lignin content by silencing genes of CCR and CAD. Acta Prataculturae Sinica, 22 (5), 72-83.

Huffman, W., and McCluskey, J. (2017). Food labels, information, and trade in GMOs. J. Agric. Food Ind. Organ. 15, 1. doi: 10.1515/jafio-2016-0038

Hundleby, P. A., and Harwood, W. A. (2019). Impacts of the EU GMO regulatory framework for plant genome editing. Food Energy Secur. 8 (2), e00161. doi: $10.1002 /$ fes 3.161

I.S.A.A.A. (2017). Global status of commercialized biotech/GM crops in 2017: biotech crop adoption surges as economic benefits accumulate in 22 years.

ILSI (2007). Best practices for the conduct of animal studies to evaluate crops genetically modified for output traits. Int. Life Sci. Inst. Washington DC.

Iwobi, A., Gerdes, L., Busch, U., and Pecoraro, S. (2016). Droplet digital PCR for routine analysis of genetically modified foods (GMO)-A comparison with real-time quantitative PCR. Food Control 69, 205-213. doi: 10.1016/j. foodcont.2016.04.048

Jacobsen, E., and Schouten, H. J. (2009). Cisgenesis: an important sub-invention for traditional plant breeding companies. Euphytica 170, 235-247. doi: 10.1007/ s10681-009-0037-y

Jain, M., Olsen, H. E., Paten, B., and Akeson, M. (2016). The Oxford Nanopore MinION: delivery of nanopore sequencing to the genomics community. Genome Biol. 17 (1), 239. doi: 10.1186/s13059-016-1103-0

Jennings, J. C., Whetsell, A. J., Nicholas, N. R., Sweeney, B. M., Klaften, M. B., Kays, S. B., et al. (2003). Determining whether transgenic or endogenous plant DNA is detectable in dairy milk or beef organs. Bull. Int. Dairy Fed. 383, 41-46. doi: $10.2527 / 2003.8161447 \mathrm{x}$

Jones, H. D. (2015). Regulatory uncertainty over genome editing. Nat. Plants 1 (14011), 10-1038. doi: 10.1038/nplants.2014.11

König, A., Cockburn, A., Crevel, R. W. R., Debruyne, E., Grafstroem, R., Hammerling, U., et al. (2004). Assessment of the safety of foods derived from genetically modified (GM) crops. Food Chem. Toxicol. 42 (7), 1047-1088. doi: 10.1016/j.fct.2004.02.019

Köppel, R., Bucher, T., Frei, A., and Waiblinger, H.-U. (2015). Droplet digital PCR versus multiplex real-time PCR method for the detection and quantification of DNA from the four transgenic soy traits MON87769, MON87708, MON87705 
and FG72, and lectin. Eur. Food Res. Technol. 241, 521-527. doi: 10.1007/ s00217-015-2481-3

Klümper, W., and Qaim, M. (2014). A meta-analysis of the impacts of genetically modified crops. PloS One 9 (11), e111629. doi: 10.1371/journal.pone.0111629

Kononov, M. E., Bassuner, B., and Gelvin, S. B. (1997). Integration of T-DNA binary vector 'backbone' sequences into the tobacco genome: evidence for multiple complex patterns of integration. Plant J. 11 (5), 945-957. doi: 10.1046/j.1365-313X.1997.11050945.x

Kovalic, D., Garnaat, C., Guo, L., Yan, Y., Groat, J., Silvanovich, A., et al. (2012). The use of next generation sequencing and junction sequence analysis bioinformatics to achieve molecular characterization of crops improved through modern biotechnology. Plant Genome 5 (3), 149-163. doi: 10.3835/ plantgenome2012.10.0026

Kumar, M., Singh, S. P., Kumar, M., Kumar, A., Kumar, S., and Kumari, P. (2018). Biosafety issues in commercialization and development of transgenic crops. Int. J. Curr. Microbiol. App. Sci. 7 (4), 2161-2174. doi: 10.20546/ijcmas.2018.704.246

Kuparinen, A., Schurr, F., Tackenberg, O., and O'Hara, R. B. (2007). Air-mediated pollen flow from genetically modified to conventional crops. Ecol. Appl. 17 (2), 431-440. doi: 10.1890/05-1599

Laaninen, T. (2016). New plant-breeding techniques: Applicability of GM rules (Briefing) (Brussels: European Parliamentary Research Service (EPRS)). Available on the World Wide Web: http://www.europarl.europa.eu/RegData/ etudes/BRIE/2016/582018/EPRS_BRI(2016)582018_EN.pdf.

Ladics, G. S., Knippels, L. M. J., Penninks, A. H., Bannon, G. A., Goodman, R. E., and Herouet-Guicheney, C. (2010). Review of animal models designed to predict the potential allergenicity of novel proteins in genetically modified crops. Regul. Toxicol. Pharmacol. 56 (2), 212-224. doi: 10.1016/j.yrtph.2009.09.018

Lee, M. R. F., Merry, R. J., Davies, D. R., Moorby, J. M., Humphreys, M. O., Theodorou, M. K., et al. (2003). Effect of increasing availability of water-soluble carbohydrates on in vitro rumen fermentation. Anim. Feed Sci. Technol. 104, 59-70. doi: 10.1016/S0377-8401(02)00319-X

Levitsky, E. L. (2016). Problem of genetically modified foods safety: a toxicologists view. Biotechnol. Acta 9 (1), 7-25. doi: 10.15407/biotech9.01.007

Li, X., He, X. L. Y., Xiao, G., Jiang, X., and Huang, K. (2008). Comparative analysis of nutritional composition between herbicide-tolerant rice with bar gene and its non-transgenic counterpart. J. Food Compos Anal. 21, 535-539. doi: 10.1016/j.jfca.2008.06.001

Li, R., Quan, S., Yan, X., Biswas, S., Zhang, D., and Shi, J. (2017). Molecular characterization of genetically modified crops: challenges and strategies. Biotechnol. Adv. 35 (2), 302-309. doi: 10.1016/j.biotechadv.2017.01.005

Liang, C., van-Dijk, J. P., Scholtens, I. M., Staats, M., Prins, T. W., Voorhuijzen, M. M., et al. (2014). Detecting authorized and unauthorized genetically modified organisms containing vip3A by real-time PCR and next-generation sequencing. Anal. Bioanal. Chem. 406 (11), 2603-2611. doi: 10.1007/ s00216-014-7667-1

Lin, C. H., and Pan, T. M. (2016). Perspectives on genetically modified crops and food detection. J. Food Drug Anal. 24 (1), 1-8. doi: 10.1016/j.jfda.2015.06.011

Loo, J. F. C., But, G. W. C., Kwok, H. C., Lau, P. M., Kong, S. K., Ho, H. P., et al. (2019). A rapid sample-to-answer analytical detection of genetically modified papaya using loop-mediated isothermal amplification assay on lab-on-a-disc for field use. Food Chem. 274, 822-830. doi: 10.1016/j.foodchem.2018.09.049

Loose, M., Malla, S., and Stout, M. (2016). Real-time selective sequencing using nanopore technology. Nat. Methods 13 (9), 751. doi: 10.1038/nmeth.3930

Loureiro, I., Garcia-Ruiz, E., Gutierrez, E., Gomez, P., Escorial, M. C., and Chueca, M. C. (2016). Pollen-mediated gene flow in the cultivation of transgenic cotton under experimental field conditions in Spain. Ind. Crops Prod. 85, 22-28. doi: 10.1016/j.indcrop.2016.02.045

Mallory-Smith, C., Hall, L. M., and Burgos, N. R. (2015). Experimental Methods to Study Gene Flow. Weed Sci. 63, 12-22. doi: 10.1614/WS-D-13-00064.1

Marsteller, N., Bøgh, K. L., Goodman, R. E., and Epstein, M. M. (2015). A review of animal models used to evaluate potential allergenicity of genetically modified organisms (GMOs). Drug Discovery Today: Dis. Models 17, 81-88. doi: 10.1016/j.ddmod.2016.11.001

Messeguer, J. (2003). Gene flow assessment in transgenic plants. Plant Cell Tissue Organ Cult. 73 (3), 201-212. doi: 10.1023/A:1023007606621

Metje-Sprink, J., Sprink, T., and Hartung, F. (2020). Genome-edited plants in the field. COBIOT, 61, 1-6.

Miller, P. (1768). Gardeners' Dictionary, 8th ed., London.
Mitsuda, N., Takiguchi, Y., Shikata, M., Sage-Ono, K., Ono, M., Sasaki, K., et al. (2011). The new FioreDB database provides comprehensive information on plant transcription factors and phenotypes induced by CRES-T in ornamental and model plants. Plant Biotechnol. J. 28 (2), 123-130.

Moreno, F. J., and Clemente, A. (2008). 2S Albumin storage proteins: what makes them food allergens? Open Biochem. J. 2, 16-28. doi: 10.2174/1874091X00802010016

Nadal, A., De Giacomo, M., Einspanier, R., Kleter, G., Kok, E., McFarland, S., et al. (2018). Exposure of livestock to GM feeds: detectability and measurement. Food Chem. Toxicol. 117, 13-35. doi: 10.1016/j.fct.2017.08.032

Naegeli, H., Birch, A.N., Casacuberta, J., De Schrijver, A., Gralak, M.A., Guerche, P., et al. (2017). Guidance on allergenicity assessment of genetically modified plants. EFSA J. 15 (6), e04862. doi: 10.2903/j.efsa.2017.4862

Nguyen, P. L., Sudheesh, P. S., Thomas, A. C., Sinnesael, M., Haman, K., and Cain, K. D. (2018). Rapid detection and monitoring of flavobacterium psychrophilum in water by using a handheld, field-portable quantitative PCR system. J. Aquat. Anim. Health 30 (4), 302-311. doi: 10.1002/aah.10046

Nicolia, A., Manzo, A., Veronesi, F., and Rosellini, D. (2014). An overview of the last 10 years of genetically engineered crop safety research. Crit. Rev. In Biotechnol. 34 (1), 77-88. doi: 10.3109/07388551.2013.823595

Niu, C., Xu, Y., Zhang, C., Zhu, P., Huang, K., Luo, Y., et al. (2018). Ultrasensitive single fluorescence-labeled probe-mediated single universal primer-multiplexdroplet digital polymerase chain reaction for high-throughput genetically modified organism screening. Anal. Chem. 90 (9), 5586-5593. doi: 10.1021/acs. analchem. $7 \mathrm{~b} 03974$

OECD. (1993). Safety evaluation of foods derived by modern biotechnology: concepts and principles. Organisation for Economic Co-operation and Development (OECD), Paris.

OECD. (1995). Guideline for the testing of chemicals, Guideline 407. Repeated dose 28-day oral toxicity study in rodents. Paris, Organization for Economic Co-operation and Development. http://www.oecd.org/ dataoecd/50/18/37478478.pdf.

OECD. (1998). OECD series on principles of good laboratory practice and compliance monitoring number 1. ENV/MC/CHEM(98)17. Paris, Organization for Economic Cooperation and Development. http://www.olis. oecd.org/olis/1998doc.nsf/LinkTo/env-mcchem(98)17.

OECD. (2000). Consensus documents for the work on the safety of novel foods and feeds. Organisation for Economic Co-operation and Development. https:// www.oecd.org/chemicalsafety/biotrack/consensus-documents-safety-ofnovel-foods-and-feeds.htm.

OECD. (2003). Considerations for the safety assessment of animal feedstuffs derived from genetically modified plants. Organisation for Economic Cooperation and Development, Paris. https://www.oecd.org/env/ehs/biotrack/46815216.pdf.

Office of the Gene Technology Regulator (OGTR). (2019). Regulations review. April 2019. http://www.ogtr.gov.au/internet/ogtr/publishing.nsf/Content/ reviewregulations-1.

Panel on Genetically Modified Organisms. (2010). Guidance on the environmental risk assessment of genetically modified plants. EFSA J. 8 (11), 1879. doi: 10.2903/j.efsa.2010.1879

Panter, S., Chu, P. G., Ludlow, E., Garrett, R., Kalla, R., Jahufer, M. Z. Z., et al. (2012). Molecular breeding of transgenic white clover (Trifolium repens $L$.) with field resistance to alfalfa mosaic virus through the expression of the AMV coat protein. Transgenic Res. 21, 619-632. doi: 10.1007/ s11248-011-9557-z

Panter, S., Mouradov, A., Badenhorst, P., Martelotto, L., Griffith, M., Smith, K. F., et al. (2017). Re-programming photosynthetic cells of perennial ryegrass (Lolium perenne L.) for fructan biosynthesis through transgenic expression of fructan biosynthetic genes under the control of photosynthetic promoters. Agronomy 7 (2), 36. doi: 10.3390/agronomy7020036

Park, D., Park, S. H., Ban, Y. W., Kim, Y. S., Park, K. C., Kim, N. S., et al. (2017). A bioinformatics approach for identifying transgene insertion sites using whole genome sequencing data. BMC Biotechnol. 17 (1), 67. doi: 10.1186/ s12896-017-0386-x

Pauwels, K., De-Keersmaecker, S., De-Schrijver, A., Du-Jardin, P., Roosens, N., and Herman, P. (2015). Next-generation sequencing as a tool for the molecular characterisation and risk assessment of genetically modified plants Added value or not? Trends In Food Sci. Technol. 45, 319-326. doi: 10.1016/j. tifs.2015.07.009 
Phipps, R. H., Beever, D. E., and Humphries, D. J. (2002). Detection of transgenic DNA in milk from cows receiving herbicide tolerant (CP4EPSPS) soybean meal. Livest. Prod. Sci. 74, 269-273. doi: 10.1016/S0301-6226(02)00038-6

Phipps, R. H., Deaville, E. R., and Maddison, B. C. (2003). Detection of transgenic and endogenous plant DNA in rumen fluid, duodenal digesta, milk, blood, and faeces of lactating dairy cows. J. Dairy Sci. 86, 4070-4078. doi: 10.3168/jds. S0022-0302(03)74019-3

Phipps, R. H., Jones, A. K., Tingey, A. P., and Abeyasekera, S. (2005). Effect of corn silage from an herbicide-tolerant genetically modified variety on milk production and absence of transgenic DNA in milk. J. Dairy Sci. 88, 28702878. doi: 10.3168/jds.S0022-0302(05)72968-4

Putnam, D. H., Woodward, T., Reisen, P., and Orloff, S. (2016). Coexistence and market assurance for production of non-genetically engineered alfalfa hay and forage in a biotech era. Crop Forage Turfgrass Manage. 2, 1. doi: 10.2134/ cftm2015.0164

Rački, N., Dreo, T., Gutierrez-Aguirre, I., Blejec, A., and Ravnikar, M. (2014). Reverse transcriptase droplet digital PCR shows high resilience to PCR inhibitors from plant, soil and water samples. Plant Methods 10 (1), 42. doi: 10.1186/s13007-014-0042-6

Ramessar, K., Peremarti, A., Gómez-Galera, S., Naqvi, S., Moralejo, M., Munoz, P., et al. (2007). Biosafety and risk assessment framework for selectable marker genes in transgenic crop plants: a case of the science not supporting the politics. Transgenic Res. 16, 261-280. doi: 10.1007/s11248-007-9083-1

Ramessar, K., Capell, T., Twyman, R. M., and Christou, P. (2010). Going to ridiculous lengths-European coexistence regulations for GM crops. Nat. Biotechnol. 28 (2), 133-136. doi: 10.1038/nbt0210-133

Reichman, J. R., Watrud, L. S., Lee, E. H., Burdick, C. A., Bollman, M. A., Storm, M. J., et al. (2006). Establishment of transgenic herbicide-resistant creeping bentgrass (Agrostis stolonifera L.) in non-agronomic habitats. Mol. Ecol. 15 (13), 4243-4255. doi: 10.1111/j.1365-294X.2006.03072.x

Ren, R., Wang, H., Guo, C., Zhang, N., Zeng, L., Chen, Y., et al. (2018). Widespread whole genome duplications contribute to genome complexity and species diversity in angiosperms. Mol. Plant 11 (3), 414-428. doi: 10.1016/j. molp.2018.01.002

Ricroch, A. E. (2013). Assessment of GE food safety using '-omics' techniques and long-term animal feeding studies. New Biotechnol. 30 (4), 349-354. doi: 10.1016/j.nbt.2012.12.001

Rizov, I., and Rodriguez-Cerezo, E. (2015). Best Practice Documents for coexistence of genetically modified soybean crops with conventional and organic farming, EUR $26780 \mathrm{EN}$, ISBN 978-92-79-39542-0.

Rizzi, A., Raddadi, N., Sorlini, C., Nordgrd, L., Nielsen, K. M., and Daffonchio, D. (2012). The stability and degradation of dietary DNA in the gastrointestinal tract of mammals: implications for horizontal gene transfer and the biosafety of GMOs. Crit. Rev. In Food Sci. Nutr. 52 (2), 142-161. doi: $10.1080 / 10408398.2010 .499480$

Rommens, C. M., Haring, M. A., Swords, K., Davies, H. V., and Belknap, W. R. (2007). The intragenic approach as a new extension to traditional plant breeding. Trends Plant Sci. 12, 397-403. doi: 10.1016/j.tplants.2007.08.001

Rooney, W. L., Blumenthal, J., Bean, B., and Mullet, J. E. (2007). Designing sorghum as a dedicated bioenergy feedstock. Biofuel. Bioprod. Biorefin. 1 (2), 147-157.

Russell, J. A., Campos, B., Stone, J., Blosser, E. M., Burkett-Cadena, N., and Jacobs, J. L. (2018). Unbiased strain-typing of arbovirus directly from mosquitoes using nanopore sequencing: a field-forward biosurveillance protocol. Sci. Rep. 8 (1), 5417. doi: 10.1038/s41598-018-23641-7

Sajjad, A. M., Yasmeen, A., Ahmad, S., and Sagheer, U. (2014). Determination of the persistence frequency of different components of the crylAc transgene cassette in mammalian tissues. J. Int. Sci. Publ. Agric. Food. 2, 448-456.

Sakadevan, K., and Nguyen, M. L. (2017). Livestock production and its impact on nutrient pollution and greenhouse gas emissions. Adv. Agron. 141, 147-184. https:// www.sciencedirect.com/science/article/pii/S0065211316301080?via\%3Dihub

Salisu, I. B., Shahid, A. A., Yaqoob, A., Ali, Q., Bajwa, K. S., Rao, A. Q., et al. (2017). Molecular approaches for high throughput detection and quantification of genetically modified crops: a review. Front. In Plant Sci. 8, 1670. doi: 10.3389/ fpls.2017.01670

SanJuan-Badillo, A., Galvez, A., Plasencia, J., and Quirasco, M. (2014). Assessment of DNA extraction methods from various maize (Zea mays L.) tissues for environmental GMO monitoring in Mexico. Part I: detection by end-point PCR. Agrociencia 48 (1), 17-33.
Sanvido, O., Widmer, F., Winzeler, M., Streit, B., Szerencsits, E., \& Bigler, F. (2008). Definition and feasibility of isolation distances for transgenic maize cultivation. Transgenic Res. 17 (3), 317-335.

Secretariat of the Convention on Biological Diversity. (2000). Cartagena protocol on biosafety to the convention on biological diversity: text and annexes. Montreal, Quebec, Canada. ISBN 92-807-1924-6.

Seyran, E., and Craig, W. (2018). New breeding techniques and their possible regulation. AgBioForum 21 (1), 1-12. http://agbioforum.org/v21n1/v21n1a01seyran.pdf

Sharma, R., Alexander, T. W., John, S. J., Forster, R. J., and McAllister, T. A. (2004). Relative stability of transgene DNA fragments from GM rapeseed in mixed ruminal cultures. Br. J. Nutr. 91 (5), 673-681. doi: 10.1079/ BJN20041100

Shaw, C. H., Carter, G. H., Watson, M. D., and Shaw, C. H. (1984). A functional map of the nopaline synthase promoter. Nucleic Acids Res. 12 (20), 7831-7846. doi: 10.1093/nar/12.20.7831

Singh, M., Bhoge, R. K., Nain, S., and Randhawa, G. (2019). Loop-mediated isothermal amplification: a rapid detection method for rice actin and nopaline synthase promoters in genetically modified crops. J. Plant Biochem. Biotechnol. 28 (3), 353-356, doi: 10.1007/s13562-018-0479-1

Slatkin, M. (1987). Gene flow and the geographic structure of natural populations. Science 236 (4803), 787-792. doi: 10.1126/science. 3576198

Smith, K., and Spangenberg, G. (2016). Considerations for managing agricultural co-existence between transgenic and non-transgenic cultivars of outcrossing perennial forage plants in dairy pastures. Agronomy 6 (4), 59. doi: 10.3390/ agronomy6040059

Smith, K. F., Forster, J. W., and Spangenberg, G. C. (2007). Converting genomic discoveries into genetic solutions for dairy pastures: an overview. Aust. J. Exp. Agric. 47 (9), 1032-1038. doi: 10.1071/EA06065

Snell, C., Bernheim, A., Berge, J. B., Kuntz, M., Pascal, G., Paris, A., et al. (2012). Assessment of the health impact of GM plant diets in long-term and multigenerational animal feeding trials: a literature review. Food Chem. Toxicol. 50, 1134-1148. doi: 10.1016/j.fct.2011.11.048

Songstad, D. D., Petolino, J. F., Voytas, D. F., and Reichert, N. A. (2017). Genome editing of plants. Crit. Rev. In Plant Sci. 36 (1), 1-23. doi: $10.1080 / 07352689.2017 .1281663$

Sprink, T., Eriksson, D., Schiemann, J., and Hartung, F. (2016). Regulatory hurdles for genome editing: process- vs. product-based approaches in different regulatory contexts. Plant Cell Rep. 35 (7), 1493-1506. doi: 10.1007/s00299-016-1990-2

Staniland, B. K., McVetty, P. B., Friesen, L. F., Yarrow, S., Freyssinet, G., and Freyssinet, M. (2000). Effectiveness of border areas in confining the spread of transgenic Brassica napus pollen. Can. J. Plant Sci. 80 (3), 521-526. doi: 10.4141/P99-117

Swiatkiewicz, S., Swiatkiewicz, M., Arczewska-Wlosek, A., and Jozefiak, D. (2014). Genetically modified feeds and their effect on the metabolic parameters of food-producing animals: a review of recent studies. Anim. Feed Sci. Technol. 198, 1-19. doi: 10.1016/j.anifeedsci.2014.09.009

Tang, M., He, X., Luo, Y., Ma, L., Tang, X., and Huang, K. (2013). Nutritional assessment of transgenic lysine-rich maize compared with conventional quality protein maize. J. Sci. Food Agric. 93, 1049-1054. doi: 10.1002/ jsfa. 5845

Tiwari, A., and Singh, K. N. (2018). Transgene copy number. J. Pharmacogn. Phytochem. 7 (2), 1829-1835. http://www.phytojournal.com/archives/2018/ vol7issue2/PartZ/7-2-254-144.pdf

Tsatsakis, A. M., Nawaz, M. A., Tutelyan, V. A., Golokhvast, K. S., Kalantzi, O. I., Chung, D. H., et al. (2017). Impact on environment, ecosystem, diversity and health from culturing and using GMOs as feed and food. Food Chem. Toxicol. 107, 108-121. doi: 10.1016/j.fct.2017.06.033

Tudisco, R., and Infascelli, F. (2014). The nutritional assessment of GMOs before commercialisation, how to approach a comprehensive assessment. World Rev. Sci. Technol. Sustain. Dev. 11 (1), 61-70. doi: 10.1504/WRSTSD.2014.062383

Turkec, A., Kazan, H., Karacanli, B., and Lucas, S. J. (2015). DNA extraction techniques compared for accurate detection of genetically modified organisms (GMOs) in maize food and feed products. J. Food Sci. Technol. 52 (8), 51645171. doi: $10.1007 / \mathrm{s} 13197-014-1547-8$

Tutel'yan, V. A. (2017). Ensuring the safety of genetically engineered and modified organisms for food production. Herald Russian Acad. Sci. 87 (2), 120-124. doi: $10.1134 /$ S1019331617020174 
UCD Centre for Food Safety, Dublin, Ireland, Van Hoorde, K., and Butler, F. (2018). Use of next-generation sequencing in microbial risk assessment. EFSA J. 16, e16086. doi: 10.2903/j.efsa.2018.e16086

Urnov, F. D., Ronald, P. C., and Carroll, D. (2018). A call for science-based review of the European court's decision on gene-edited crops. Nat. Biotechnol. 36 (9), 800. doi: $10.1038 /$ nbt. 4252

Urquiza, M. P., and Silva, A. A. (2014). Copy number ratios determined by two digital polymerase chain reaction systems in genetically modified grains. Metrologia 51 (1), 61. doi: 10.1088/0026-1394/51/1/61

Van-Deynze, A., Putnam, D. H., Orloff, S., Lanini, T., Canevari, M., Vargas, R., et al. (2004). Roundup ready alfalfa: an emerging technology. Retrieved from https://escholarship.org/uc/item/3fk3h0z0 doi: 10.3733/ucanr.8153.

Van-Deynze, A. E., Sundstrom, F. J., and Bradford, K. J. (2005). Pollen-mediated gene flow in California cotton depends on pollinator activity. Crop Sci. 45 (4), 1565-1570. doi: 10.2135/cropsci2004.0463

Van-Eenennaam, A. L., and Young, A. E. (2014). Prevalence and impacts of genetically engineered feedstuffs on livestock populations. J. Anim. Sci. 92 (10), 4255-4278. doi: 10.2527/jas.2014-8124

Van-Eenennaam, A. L., and Young, A. E. (2017). Detection of dietary DNA, protein, and glyphosate in meat, milk, and eggs. J. Anim. Sci. 95 (7), 3247-3269. doi: $10.2527 /$ jas 2016.1346

Van-Haver, E., De -Schrijver, A., Devos, Y., Lievens, S., Renckens, S., and Moens, W. (2003). The safety assessment of genetically modified crops for food and feed use. Guidance notes from the Service of Biosafety and Biotechnology and Biosafety council in Belgium. Available at: http://www. biosafety.be/NF/NFMenu.html.

Venus, T. J., Drabik, D., and Wesseler, J. (2018). The role of a German multistakeholder standard for livestock products derived from non-GMO feed. Food Policy. 78, 58-67. doi: 10.1016/j.foodpol.2018.02.009

Wang, Z. Y., Lawrence, R., Hopkins, A., Bell, J., and Scott, M. (2004). Pollenmediated transgene flow in the wind-polli- nated grass species tall fescue (Festuca arundinacea Schreb.). Mol. Breed. 14, 47-60. doi: 10.1023/B:M OLB.0000037994.26287.17

Warwick, S. I., Beckie, H. J., and Hall, L. M. (2009). Gene flow, invasiveness, and ecological impact of genetically modified crops. Year In Evol. Biol. 1168, 72-99. doi: 10.1111/j.1749-6632.2009.04576.x

Wehrmann, A., Van-Vliet, A., Opsomer, C., Botterman, J., and Schulz, A. (1996). The similarities of bar and pat gene products make them equally applicable for plant engineers. Nat. Biotechnol. 14 (10), 1274-1278. doi: 10.1038/nbt1096-1274

Weirather, J. L., de-Cesare, M., Wang, Y., Piazza, P., Sebastiano, V., Wang, X. J., et al. (2017). Comprehensive comparison of Pacific Biosciences and Oxford
Nanopore Technologies and their applications to transcriptome analysis. Research 6. doi: 10.12688/f1000research.10571.2

Wiedinmyer, C., Strange, I. W., Estes, M., Yarwood, G., and Allen, D. T. (2000). Biogenic hydrocarbon emission estimates for North Central Texas. Atmos. Environ. 34 (20), 3419-3435.

Willems, S., Fraiture, M. A., Deforce, D., De Keersmaecker, S. C., De Loose, M. Ruttink, T., et al. (2016). Statistical framework for detection of genetically modified organisms based on next generation sequencing. Food Chem. 192, 788-798. doi: 10.1016/j.foodchem.2015.07.074

Wilson, H., and Manhart, J. (1993). Crop/weed gene flow: Chenopodium quinoa Willd. and C. berlandieri Moq. Theor. Appl. Genet. 86 (5), 642-648. doi: 10.1007/BF00838721

Wolt, J. D. (2017). "Safety, security, and policy considerations for plant genome editing," in Progress in molecular biology and translational science (Academic Press), vol. 149, pp. 215-241.

Wolt, J. D., Wang, K., and Yang, B. (2015). The regulatory status of genome-edited crops. Plant Biotechnol. J. 14 (2), 510-518. doi: 10.1111/pbi.12444

World Hunger. (2013). https://www.worldhunger.org/articles/Learn/old/world\%20 hunger\%20facts\%202002_2012version.htm.

Yang, L., Ding, J., Zhang, C., Jia, J., Weng, H., Liu, W., et al. (2005). Estimating the copy number of transgenes in transformed rice by real-time quantitative PCR. Plant Cell Rep. 23 (10-11), 759-763. doi: 10.1007/s00299-004-0881-0

Yang, L., Wang, C., Holst-Jensen, A., Morisset, D., Lin, Y., and Zhang, D. (2013). Characterization of GM events by insert knowledge adapted re-sequencing approaches. Sci. Rep. 3, 2839. doi: 10.1038/srep02839

Zhang, C., Wohlhueter, R., and Zhang, H. (2016). Genetically modified foods: a critical review of their promise and problems. Food Sci. Hum. Wellness 5 (3), 116-123. doi: 10.1016/j.fshw.2016.04.002

Conflict of Interest: The authors declare that the research was conducted in the absence of any commercial or financial relationships that could be construed as a potential conflict of interest.

Copyright (c) 2019 Giraldo, Shinozuka, Spangenberg, Cogan and Smith. This is an open-access article distributed under the terms of the Creative Commons Attribution License (CC BY). The use, distribution or reproduction in other forums is permitted, provided the original author(s) and the copyright owner(s) are credited and that the original publication in this journal is cited, in accordance with accepted academic practice. No use, distribution or reproduction is permitted which does not comply with these terms. 